\title{
INDUCED SEISMICITY IN \\ GEOTHERMAL RESERVOIRS: A \\ REVIEW OF FORECASTING APPROACHES
}

Emmanuel Gaucher ${ }^{a^{*}}$, Martin Schoenball ${ }^{b}$, Oliver Heidbach ${ }^{c}$, Arno Zang ${ }^{c}$, Peter A. Fokker ${ }^{d}$, Jan-Diederik van Wees ${ }^{\mathrm{d}, \mathrm{e}}$, Thomas Kohl ${ }^{\mathrm{a}}$

a Karlsruhe Institute of Technology, Institute of Applied Geosciences, Division of Geothermal Research, Adenauerring 20b, 76131 Karlsruhe, Germany

${ }^{b}$ Karlsruhe Institute of Technology, Institute of Applied Geosciences, Division of Geothermal Research, Adenauerring 20b, 76131 Karlsruhe, Germany; now at Earth and Environmental Science, Temple University, Philadelphia, USA and U.S. Geological Survey, Menlo Park, USA

${ }^{c}$ Helmholtz Centre Potsdam, GFZ German Research Centre for Geosciences, Section 2.6, Helmholtzstraße 6/7, 14467 Potsdam, Germany

d TNO, P.O. Box 80015, NL-3508 TA Utrecht, The Netherlands

${ }^{e}$ Utrecht University, Faculteit van Aardwetenschappen, Boedapestlaan 4, The Netherlands

": Corresponding author. Phone: +49 721608 45223, Fax: +49 721608 45228, Email: emmanuel.gaucher@kit.edu 


\section{TABLE OF CONTENTS}

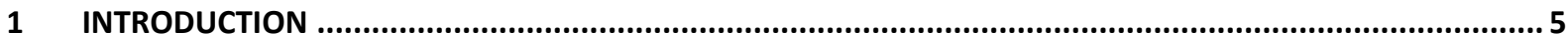

2 DEVELOPMENT OF MODELS TO FORECAST INDUCED SEISMICITY ........................................................ 6

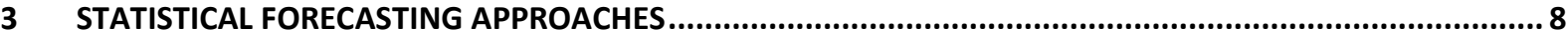

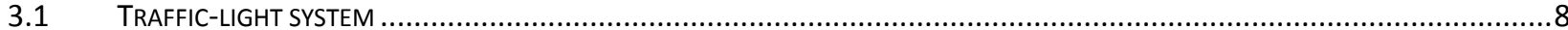

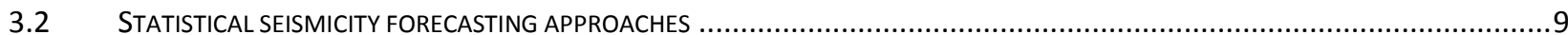

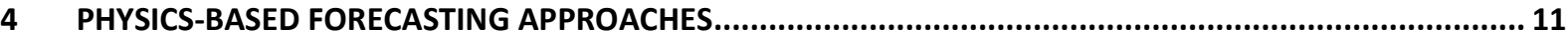

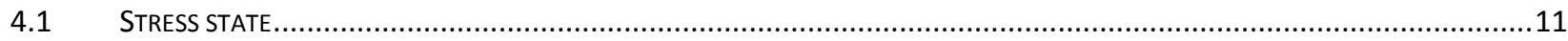

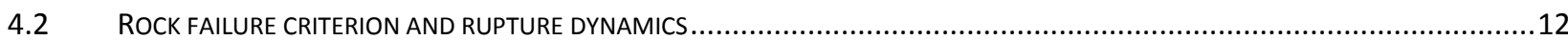

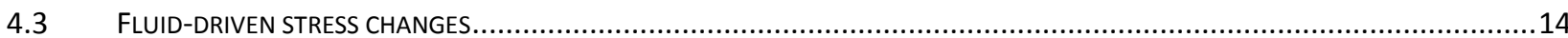

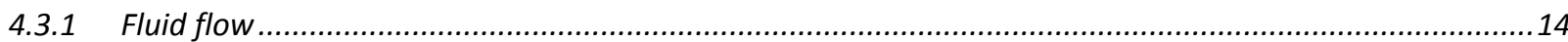

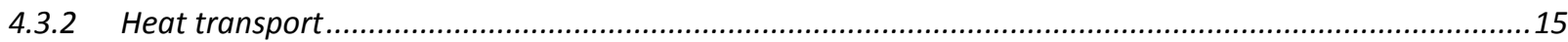

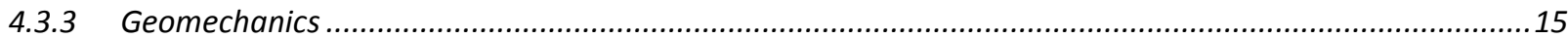

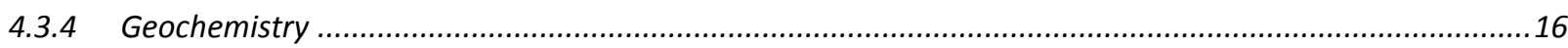

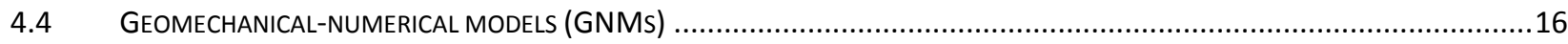

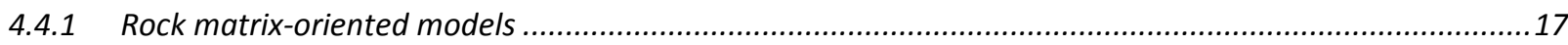

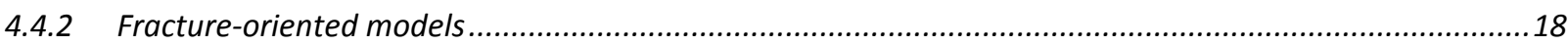

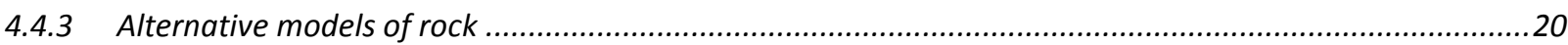

4.4.4 Bridging deterministic and probabilistic approaches ......................................................................21

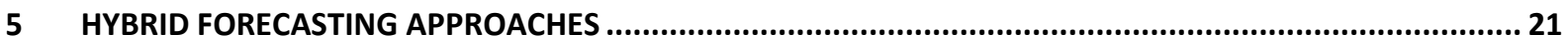

6 APPLICABILITY AND LIMITATIONS OF CURRENT APPROACHES....................................................... 23

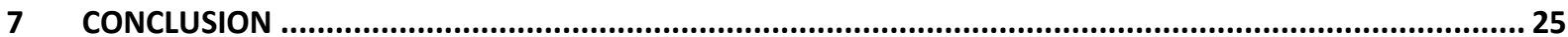

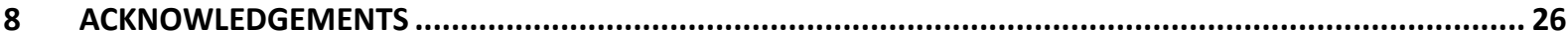

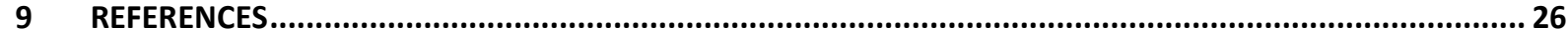


In order to reach Europe's 2020 and 2050 targets in terms of greenhouse gas emissions, geothermal resources will have to contribute substantially to meeting carbon-free energy needs. However, public opinion may prevent future large-scale application of deep geothermal power plants, because induced seismicity is often perceived as an unsolicited and uncontrollable side effect of geothermal development. In the last decade, significant advances were made in the development of models to forecast induced seismicity, which are either based on catalogues of induced seismicity, on the underlying physical processes, or on a hybrid philosophy. In this paper, we provide a comprehensive overview of the existing approaches applied to geothermal contexts. This overview will outline the advantages and drawbacks of the different approaches, identify the gaps in our understanding, and describe the needs for geothermal observations. Most of the forecasting approaches focus on the stimulation phase of enhanced geothermal systems which are most prone to generate seismic events. Besides the statistical models suited for real-time applications during reservoir stimulation, the physics-based models have the advantage of considering subsurface characteristics and estimating the impact of fluid circulation on the reservoir. Hence, to mitigate induced seismicity during major hydraulic stimulations, application of hybrid methods in a decision support system seems the best available solution. So far, however, little attention has been paid to geochemical effects on the failure process and to production periods. Quantitative modelling of induced seismicity still is a challenging and complex matter. Appropriate resources remain to be invested for the scientific community to continue its research and development efforts to successfully forecast induced seismicity in geothermal fields. This is a prerequisite for making this renewable energy resource sustainable and accessible worldwide.

\section{KEYWORDS}

Geothermal

Forecasting

Micro-earthquake

Stimulation

Numerical modelling

Geomechanics

\section{ABBREVIATIONS}

DFN: discrete fracture network

EGS: enhanced geothermal system

ETAS: epidemic type aftershock sequence 
FISHA: forward induced seismic hazard assessment

GNM: geomechanical-numerical model

$\mathrm{M}_{\mathrm{L}}$ : local magnitude

$\mathrm{M}_{\mathrm{w}}$ : moment magnitude

PISHA: probabilistic induced seismic hazard assessment

PSHA: probabilistic seismic hazard assessment

THM(C): thermo-hydro-mechanical(-chemical) 


\section{INTRODUCTION}

Geothermal energy is able to provide base-load power for electricity and heat generation in many countries around the world. Its share in meeting the global power need is predicted to be 3 to $4 \%$ in 2050 [1]. Currently, the vast majority of geothermal energy is being produced commercially from hydrothermal and magmatic systems, where hot fluids (water, brine or steam) are extracted from naturally permeable reservoir rocks. However, easily accessible geothermal systems are becoming increasingly scarce and the keys to geothermal energy growth are the development of so-called supercritical systems and, more importantly, enhanced geothermal systems (EGS) [1, 2]. Where fractures are not naturally abundant or permeable and matrix porosity is small, hydraulic stimulations are performed. Fluids are pumped to several kilometres depth under high pressure to create or reactivate fractures and faults. Such an operation aims at increasing the reservoir permeability to eventually provide economic flow rates of high-temperature geothermal fluids. Hence, EGS are less dependent on site-specific hydrogeological conditions than conventional hydrothermal systems. Since only a few EGS exist around the world to date, more experience is required to prove that they would be an economically viable solution to provide energy [3].

In the course of the geothermal power production and permeability enhancement, seismicity is frequently induced. Fluid injection, forced fluid circulation or fluid withdrawal is responsible for it. This effect has been known for more than 30 years, e.g. [4, 5], and has been observed in areas, such as Indonesia, the Philippines, Japan, North and South America, and New Zealand. In most cases of induced seismicity, many events are generated each year, usually with magnitudes smaller than $\mathrm{M}_{\mathrm{L}}=3$ and hence without economic consequences. With the development of the first EGS, induced seismicity in geothermal fields attracted larger interest. In Central Europe, several field cases induced seismicity to a level felt by the population. In Basel city, Switzerland, the stimulation of the first well of what should have been a deep geothermal doublet induced an $\mathrm{M}_{\mathrm{L}}=3.4$ event in Dec. 2006 [6]. The occurrence of this event and the seismic risk analysis which followed [7] led to the abandonment of the project. In Landau, Germany, an $\mathrm{M}_{\mathrm{L}}=2.7$ event occurred in Aug. 2009 during geothermal circulation [8]. More recently, in Jul. 2013, the stimulation of the first deep well of the St. Gallen geothermal project (Switzerland) induced an $\mathrm{M}_{\mathrm{L}}=3.5$ event which was also felt by the local population [9]. Similar fluid-driven perturbations caused by reservoir impoundment, oil and gas production and underground disposals of waste fluids also induce significant seismicity [10-14]. As a result, many efforts have been undertaken to better understand and to better forecast and mitigate induced events above a tolerable level.

Besides more systematic comparative studies of field cases, e.g. [12, 15-17], several guidelines for addressing the seismicity induced in geothermal fields and securing the population have been published [18-20]. In these reports, however, the operational aspects which influence and, consequently, could limit the occurrence of felt or large seismic events during the geothermal field development were hardly discussed. This perspective, which requires forecasting geothermal-induced seismicity and therefore development of models, was not considered. Major advances were reached in recent years in this domain, e.g. [21]. In comparison to natural seismicity forecasting, geothermal-induced seismicity forecasting is 
believed to be a simpler task, mainly because geothermal-induced seismicity is considered a transient effect having its source in man-made controllable operation parameters. Additionally, the subsurface characteristics and behaviour are usually better known, in particular with the deployment of numerous monitoring systems during the development and production phases of the reservoir, e.g. [22].

In this paper, we review the current approaches to forecasting induced events at geothermal sites. Three classes of approaches are distinguished (Figure 1). The first are the statistical approaches that reproduce catalogues of monitored induced seismicity in order to forecast seismic events in quasi real time. The second class covers physics-based approaches that model the process of stress and strain changes in the geothermal reservoir at the origin of the induced seismicity. The hybrid approach, which combines statistical with physics-based approaches, constitutes the third class of approaches.

[Recommended location of Figure 1, one column only]

We document and compare the advantages and limits of the different forecasting approaches as well as directions of ongoing developments. We do not intend to provide all the details of the numerical or statistical models behind the forecasting approaches, but focus on the key concept of each approach. This work contributes to identifying the gaps in the approaches towards understanding the link between the underground processes taking place during the geothermal activity and the generation of seismicity. Lastly, we point towards future developments and needs.

\section{DEVELOPMENT OF MODELS TO FORECAST INDUCED SEISMICITY}

There is a wide range of models that aim at forecasting induced seismicity. Different types of models use different input data, calibration data, and apply different processing schemes. However, they all are supposed to supply a synthetic catalogue of induced seismicity that is to be expected in the future for a given field. For valuable use of the generated synthetic catalogue in forecasting approaches, occurrences of induced seismic events in a given magnitude range must be specified at least. This corresponds to a time, magnitude, and possibly rate attribute for the events. Figure 2 highlights the workflow usually followed by the statistical, physics-based, and hybrid forecasting approaches. It gives an overview of which processes, properties, field parameters, and observations are involved in the associated models.

\section{[Recommended location of Figure 2, on full page width]}

With statistical approaches, seismicity forecasting only needs the observed catalogues prior to the field operation and during the field operation (blue arrows in Figure 2). The physicsbased approaches, on the contrary, will not directly use the observed catalogues, except during a calibration procedure intended to better model the structure and the properties of the geothermal reservoir (red arrows in Figure 2). Instead, they simulate the physical 
changes of the reservoir caused by the geothermal field operations. In its current state of development, the hybrid approach follows a physics-based description of the reservoir behaviour and uses catalogues of induced seismicity to constrain seismic event properties following rock failure (green arrows in Figure 2).

To obtain the synthetic catalogue, a description of the unperturbed state of the geothermal reservoir and its seismogenic behaviour is made first. For purely statistical approaches, characterizing the background seismicity prior to any geothermal field operation is sufficient. Background seismicity means natural seismicity, but also any prior induced seismicity. For physics-based and hybrid approaches (in their current state of development), the description also includes the initial geometrical features of the reservoir, its main thermo-hydromechanical properties, and the initial conditions of temperature $(T)$, pressure $(P)$, and stress field $(\sigma)$. These parameters are derived from the interpretation and analysis of numerous observations, which have been collected during the exploration phase, including well drilling. Among other disciplines, geology, geodesy, geophysics, and geomechanics are necessary to conduct the field description prior to development.

The geothermal operations, such as stimulation, injection, production or circulation, will perturb the initial state of the reservoir and potentially generate seismicity. Real-time analysis of the induced seismicity, combined with the background seismicity, is enough for statistical approaches to generate probabilistic synthetic catalogues of induced seismicity. In physicsbased approaches, the thermo-hydro-mechanical processes taking place during the field operations must be modelled. Geochemical processes which play a role, though indirectly (e.g. geothermal fluid concentration changes, reaction heat, diagenesis), should also be included. In practice, however, this is hardly ever done. Evolving from the initial steady state of the reservoir, the transient state is modelled. The stress field perturbation at the origin of the rock failure and the underlying seismic events are evaluated over space and time. Rock failure can change the properties of the reservoir, for example through the creation or the enhancement of the local fracture network. To calibrate the thermo-hydro-mechanical model, observations must be made before and during the operations. Typically, temperature, flow rate, and pressure at different wells are monitored. Physics-based approaches presently generate deterministic synthetic catalogues of forecasted induced seismicity, which means that all events of the catalogue should occur. Currently, hybrid approaches also use seismicity induced during operations to calibrate the characteristics of seismic events resulting from the rock failure model. Hence, they yield probabilistic catalogues as do the statistical approaches.

The synthetic catalogue of the forecasted induced seismicity would be used as an input for probabilistic induced seismic hazard assessment (PISHA) and a following induced seismic risk analysis, e.g. [7]. Both analyses represent the last steps in quantifying the impact on the surface and on the infrastructures of induced seismicity. A PISHA is an extension of the wellknown probabilistic seismic hazard assessment (PSHA) usually applied to natural seismicity [23]. PSHA quantifies the probability of exceeding a ground motion parameter value (e.g. peak ground velocity, peak ground acceleration) at a site in a given time span. A PSHA involves three consecutive steps: 1) Compilation of an earthquake catalogue in the area of interest and definition of local seismic source zones, e.g. [24, 25]; 2) Specification of suitable ground motion prediction equations that describe best the attenuation relationships of the seismic waves in the study area [26-29]; 3) The probabilistic calculation itself, including the quantitative 
assessment of the uncertainties due to all input parameters (i.e. aleatoric uncertainties) and the uncertainties due to the models used (i.e. epistemic uncertainties).

The compilation of the earthquake catalogue needs to account for the following issues when applied to induced seismicity. First, geothermal-induced seismicity should follow a Poisson distribution as assumed in the established PSHA. In other words, the occurrences of induced events in time and space must be independent of each other within a source zone. Although results from Langenbruch et al. [30] support this behaviour, it is only partly supported by Schoenball et al. [31]. Second, a catalogue of induced seismic events for the zone of interest has to be obtained or a synthetic catalogue has to be created. Applying a catalogue of another site would be misleading. In practice, only catalogues of induced seismicity produced during stimulation or production of geothermal reservoirs are suitable. Consequently, PSHA applied to induced seismicity must be conducted in real time and proper handling of the aleatoric and epistemic uncertainties integrated in a logic tree is required. Third, the reliability of a natural seismicity catalogue should be assessed on a spatial scale smaller than usual. For geothermal-induced seismicity, the source region typically is of the order of $10 \times 10 \mathrm{~km}^{2}$ compared to about $100 \times 100 \mathrm{~km}^{2}$ in PSHA.

Seismic hazard assessment and seismic risk cover many other aspects which are far beyond the scope of this paper. Interested readers can refer to the above-cited references for further details.

\section{STATISTICAL FORECASTING APPROACHES}

Catalogues of monitored induced seismicity can be used to predict or forecast changes of seismicity rates compared to the natural background seismicity rate. This is done by describing the general pattern of seismicity and the replication of occurrence time, magnitude, and location of seismic events.

\subsection{Traffic-light system}

To prevent the occurrence of intolerable induced seismicity in the Berlín geothermal field (El Salvador), Bommer et al. [29] implemented a reactive control approach, the so-called trafficlight system. This pragmatic approach is based on the following conceptual model of induced seismicity: given that the seismic events are induced by geothermal operations which force fluids to circulate, it should be possible to prevent any major disturbance on the surface by modifying or suspending these operations at the right moment. A suitable reaction scheme is derived from the induced seismic events unfelt by the population and recorded during the operations by a permanent seismic network. Such a traffic-light system can be implemented relatively easily and requires real-time processing of the acquired data.

A similar approach was also applied to the EGS project of Basel (Switzerland) in which the magnitude of the located events, the peak ground velocity, and the citizens' phone calls served as warning indicators [32]. The procedure was as follows: whenever the pre-defined threshold of one indicator was reached, the on-going geothermal operations had to be adapted. The actions taken to reduce seismicity could be: decreasing the fluid injection rate, decreasing the injection well head pressure, stopping injection, relieving injection well head pressure (bleedoff). Stepwise changes from a regular geothermal operation (green light, no threshold reached) 
to a full stop of the operations (red light, highest thresholds reached) were possible. So, it was inherent in the approach that well-chosen thresholds and actions could prevent unwanted seismicity. In the original Berlín geothermal field application [29], the cumulative number of seismic events was also considered as an indicator and, thus, induced seismicity was treated as a time-dependent process.

Clearly, the two most critical challenges of the traffic-light system are (1) to define adequate thresholds for each parameter and (2) to choose the right field operation that lowers the induced seismicity. A priori information is required, preferably from the location of interest. To define the seismic event magnitude thresholds for the EGS project of Basel, for example, historical seismicity had been analysed as well as seismicity induced during the stimulations of the Soultz-sous-Forêts (France) geothermal field located $\sim 180 \mathrm{~km}$ further north. The latter seismicity, together with near-surface amplification models, was also used to calculate the peak ground velocity thresholds. For the Berlín geothermal field, which is located in a seismically active area, natural seismicity was used to correlate the measured peak ground velocity with the event magnitude and hypocentre. To define the thresholds, a review of the literature discussing the human acceptance levels to vibrations was made in addition to a field study to quantify the relationship between observed structural damage induced by natural seismicity and measured peak ground velocities.

Currently, accepted specifications for establishing a traffic-light system are lacking, but the original procedures described above nowadays are considered to be too simplistic. As a matter of fact, the protocol applied to the Basel EGS did not prevent the occurrence of a felt induced seismic event after injection was stopped [32]. More accurately, an $\mathrm{M}_{\mathrm{L}}=2.6$ occurring on 8-Dec2006 triggered the orange level of the traffic-light system and injection was consequently decreased and eventually stopped. Four hours later, however, an $\mathrm{M}_{\mathrm{L}}=2.7$ event occurred and one hour later, the largest induced event of $M_{L}=3.4$ happened. This triggered the red level and the pressure in the well was relieved (bleed-off). From January to March 2007, a series of $M_{L}=2.9,3.1,3.2$, and 3.3 induced events still occurred in the area. Similar traffic-light systems would also have been inefficient if applied to the Soultz-sous-Forêts major stimulations of 2000 and 2003, where induced events with $M_{W}>2$ occurred several days after the end of injection [33]. These observations clearly underline that the time dependence of the induced events is not properly handled in these traffic-light systems. Consequently, although attractive in terms of implementation and usage, they are not considered reliable any longer to prevent seismic events of economic concerns during and after shut-in, at least in this form.

\subsection{Statistical seismicity forecasting approaches}

Statistical approaches to forecasting induced seismicity are inherited from the vast domain of statistical seismology. Readers are referred to Utsu [34] and references therein for a review of the topic. The common goal of these approaches is to describe the observed seismicity in terms of occurrence time, magnitude, and possibly location and, hence, to also forecast these characteristics. Bachmann et al. [35] developed such an approach to geothermalinduced seismicity. They tested a few statistical models to reproduce and forecast the seismicity rates induced during the reservoir stimulation of the Basel geothermal site. In this case, the location of the seismicity was not investigated. These statistical models are based on two main classical assumptions. First, the frequency-magnitude distribution of seismic events follows a Gutenberg-Richter [36] law: $\log (M)=a-b \cdot M$, where $N$ denotes the number of events recorded above a magnitude $M$; the $a$ - and $b$-values are unknowns to be estimated 
from the event catalogues. This relation describes the ratio between the large and the small events. For tectonic earthquakes, the $b$-value is typically close to 1 : there are statistically ten times more events of magnitude 2 than magnitude 3 for a given time period. Such behaviour is observed worldwide on many spatial and temporal scales in a variety of earthquake databases. However, the $b$-value can vary, and at Basel it was larger during the injection period ( 1.54) than during the post-injection period ( 1.15) [35].

The second assumption is that the time distribution of clustered events, such as mainshockaftershock sequences, can be modelled as point processes [37]. Herein, the two types of forecast models considered assume that the seismic event rate follows the modified Omori formula [38]: $n(t)=K \cdot(t+c)^{-p}$, where $n$ denotes the event rate, $t$ the time elapsed since the mainshock and $K, c$, and $p$ are unknowns to be estimated from the catalogue. It is necessary to combine this event-time distribution with an event-magnitude distribution, typically, the Gutenberg-Richter distribution. To obtain the rate of aftershocks, one combination follows the Reasenberg and Jones [39] formulation, another applies an Epidemic Type Aftershock Sequence (ETAS) model [40], in which each seismic event can generate its own sequence of aftershocks. In the first case, only the elapsed time from the first event is taken into account, while in the second case, each event occurrence time is used. In addition, a background seismicity rate is introduced for the ETAS model. Bachmann et al. [35] assumed that this background seismicity rate may be a combination of the natural seismicity rate prior to any injection activity with the injection rate taken from the operation conditions. They quantitatively compared the forecast results to the real data and identified the model accounting for the real injection rate to be the best fitting one (Figure 3 ). This conclusion illustrates that the introduction of physical considerations can improve the results.

\section{[Recommended location of Figure 3 on one column - PERMISSION GIVEN BY GJI AND AUTHOR]}

Several parameters describing the statistical seismicity models must be updated in quasi real time as data are recorded. In practice, this can be difficult for a few of these parameters, such as the $b$-value, which requires many events over a relatively large magnitude range. Hence, correct setting of statistical seismicity models is dependent on the size of the growing database at a specific site.

From the rate of aftershocks, $n\left(t, M_{m}, M_{c}\right)$, defined as the rate of events above magnitude $M_{c}$ following an event of magnitude $M_{m}$ after an elapsed time $t$, it is possible to compute the probability, $P$, of one or more events occurring in the magnitude range $M_{1} \leq M \leq M_{2}$ and time range $t_{1} \leq t \leq t_{2}$ :

$$
P=1-\exp \left[-\int_{M_{1}}^{M_{2}} \int_{t_{1}}^{t_{2}} n\left(t, M, M_{c}\right) d t d M\right]
$$

Following this line, a probability of more than $50 \%$ of inducing one or more events with $M_{L}=2$ after 1 day of injection in Basel results. After 5 days of injection, this $50 \%$ probability was reached for a $\mathrm{M}_{\mathrm{L}}=3$ seismic event and $\mathrm{M}_{\mathrm{L}}=4$ events had $7 \%$ probability of occurring (Figure 4). The probability estimate of Eq. (1) requires the selection of the maximum magnitude event (here, $\mathrm{M}_{\mathrm{WMax}}=5$ ) which could happen in the area of interest, the determination of which remains controversial, e.g. [41]. 


\section{[Recommended location of Figure 4 on one column - PERMISSION GIVEN BY GJI AND AUTHOR]}

Mena et al. [42] extended the work of Bachmann et al. [35] by adding an induced seismicity model based on pore pressure diffusion and de facto creating a hybrid model (see section 5). Consequently, another model branch was added to the Reasenberg and Jones and ETAS ones. Moreover, the performance of the individual or combined models was assessed using the magnitude-size distribution of the seismicity. They showed that the combined model performed better than any individual ones.

The characterization of Eq. (1) for a specific geothermal field allows generating a catalogue of induced seismicity, which can be integrated into a PISHA, e.g. [42-44].

\section{PHYSICS-BASED FORECASTING APPROACHES}

Physics-based forecasting approaches in geothermal fields are aimed at predicting the seismicity induced by forced fluid flow circulation in the underground based on the description and modelling of the associated physical processes. Unlike the previously described approaches, induced seismicity is not used as an input parameter. However, seismicity as a dynamic process is typically not simulated in currently physics-based models. Instead, the output of the models (stress, strain, pressure) is translated a posteriori into event occurrence.

The physical origin of a seismic event is a variation of in-situ stress driving the crust from a stable to an unstable state up to rock failure. This applies to natural, triggered, and induced seismicity. Hence, we do not discriminate triggered seismicity from induced seismicity, although the former may be initiated by a minor man-made increment of stress [45] or may release larger seismic energy [46]. In geothermal applications, the stress changes are due to the numerous coupled effects of fluid circulation within the reservoir. To assess this quantitatively, it is necessary to describe a) the initial in-situ stress state of the reservoir, b) the rock failure criterion, its friction characteristics, and the associated rupture dynamics, and c) the stress perturbation, in space and time, induced by the anthropogenic underground operations. In this section, we first discuss these subjects and then present for various geomechanical-numerical models (GNMs) how the underlying processes are integrated.

\subsection{Stress state}

Sources of stress in the Earth's crust can be classified according to their spatial and temporal scales [47]. Gravity, topography, paleotectonic and tectonic plate motion typically are largescale stationary sources of stresses. Erosion, sedimentation, the regional seismic cycle, and aseismic creep can be considered transient stress sources with intermediate spatial and temporal scales. Finally, man-made activities, such as mining, tunnelling, drilling, water impoundment, fluid injection, and production are local sources of stress (Figure 5). 
For geothermal fields, in most cases, only the stress induced by the fluid circulation within the reservoir is considered to change over time and space. The other stress sources are considered to be in a steady state and are used to quantify the natural stress. Over several ten or more years, however, this assumption may be too strong depending on the region of interest (e.g. Philippines).

The stress acting on a rock body is described formally by the stress tensor characterized by three independent orthogonal principal stresses denoted $S_{1}, S_{2}$, and $S_{3}$, where, by definition, $S_{1} \geq S_{2} \geq S_{3}$. It is generally assumed that one of the principal stresses corresponds to the vertical stress, $S_{v}$, and the other two principal stresses are the maximum and the minimum horizontal stresses $S_{H}$ and $S_{h}$, respectively. This hypothesis is justified, unless the lateral contrast in rock strength and/or density is significant. Most EGS in Europe are being developed or planned in a strike-slip $\left(S_{H}>S_{V}>S_{h}\right)$ or normal faulting $\left(S_{V}>S_{H}>S_{h}\right)$ stress regimes [48].

The World Stress Map project [49] compiles information on the contemporary orientation of $S_{H}$ in the crust, and stress magnitude compilation is under development [50]. For about $75 \%$ of the available data, the stress regime is also known. The magnitude of $S_{V}$ is usually inferred from the weight of the overburden at the considered depth, which is computed from density logs. $S_{H}$ and $S_{h}$ orientations may be estimated from borehole breakouts, drilling-induced tensile fractures, hydraulic fractures, or well tests, among others. Several of these estimation techniques also allow determining the amplitude of $S_{h}$. However, the quantification of the $S_{H}$ magnitude is only possible with a number of assumptions that imply high uncertainties of the results [51-54].

\subsection{Rock failure criterion and rupture dynamics}

The rock failure criterion defines the relationship between the material cohesion and the effective stresses acting at the point of failure. Once the critical stress is reached, either preexisting faults are reactivated or new ones are created. Several rock failure criteria exist [55]. The Mohr-Coulomb criterion [56] is well-known and widely used, because it was developed early and is supported by many observations [57]. Accordingly, at the point of failure, $T=C+$ $\mu \cdot \sigma_{n}$, where $\tau, C, \mu$, and $\sigma_{n}$ are the shear stress, the cohesion coefficient, the friction coefficient, and the effective normal stress, respectively (Figure 6). The effective stress is the stress felt by the rock grains and is the difference between the in-situ stress and the pore pressure. The cohesion is often assumed to be zero, especially when pre-existing fracture and faults are considered. Referring to Byerlee [58], the friction coefficient typically is $0.6-$ 0.85 , depending on the effective normal stress absolute value. These values hold for intact rock, for pre-existing faults, however, $\mu$ is considered to be smaller and could range between 0.3 and 0.6 , e.g. [59, 60]. In low differential effective stress regimes, mode I failure (tensile) is possible, but this is not the case for high differential effective stresses when model II failure (shear) is prevailing. A drawback of the Mohr-Coulomb criterion is that it only incorporates the minimum and the maximum principal stresses and does not account for the threedimensional nature of the stress state. Furthermore, the linearity of the failure line is a limitation of the model. Alternative criteria can indicate a strengthening influence of the intermediate stress: Lade and modified Lade criteria [61], Drucker-Prager criterion [62]. Other 
criteria are non-linearly dependent on the stress: the Hoek-Brown criterion either in 2D [63] or in 3D [64], the Griffith criterion. Benz and Schwab [65], who compare several of these criteria, suggest that an extended Hoek-Brown criterion, which exhibits both features, is a better model.

\section{[Recommended location of Figure 6, on one column]}

If the geometry of the faults and the stress field are known, it is possible to assess for a chosen failure criterion the proximity of the stress state to critical values for slip and fault rupture. These characteristics represent a helpful tool in assessing the risks of induced seismicity, e.g. [48, 59, 66-68]. They can also be used to test and validate the classical structural geology approach, for which the largest possible induced event is inferred from the largest reservoir fault that is critically stressed. Assigning a maximum event magnitude to a given fault is based on empirical relations between magnitude and fault parameters, such as length, width, and displacement [69-71]. Problems arise with empirical seismic relations when downscaling the above models to the size of fractures expected to be created or reactivated in a geothermal reservoir $\left(10^{-2}\right.$ to $\left.10 \mathrm{~km}^{2}\right)$. So far, downscaling laws have been proposed to be linear in the log-log space, but non-linear relationships may exist [72].

In tectonically active areas, crustal stresses are close to critical stress conditions for rock failure, and this is often assumed for EGS sites. As they are characterized by reduced friction compared to intact rock, active faults most likely are locations of further seismic activity. Hence, in areas with higher natural seismic hazard, the occurrence probability of induced events may also be higher for each magnitude level, as seems to be observed by Evans et al. [16].

To characterize important rupture parameters, such as stress drop and size of seismic events, it is crucial to understand the dynamics of the seismic fault rupture, which is highly dependent on the friction laws governing slip behaviour of the associated faults. According to theoretical mechanical models of earthquakes, slip results in a stress drop, which coincides with the smoothening of asperities reducing friction during faulting. At the end of the faulting process, the asperities heal and re-instate the friction. Scholz [73] described this using the widespread rate and state variable friction law of Dieterich-Ruina [74-76]. He demonstrated that the state of stress can be stable, unstable, or conditionally stable. The model is consistent with the observation that natural seismicity generally occurs deeper than 3-4 km in the crust. As one of the principal stresses usually is the vertical stress, which increases with depth, the rate and state model predicts that deeper natural earthquakes are generally characterized by higher stress drops and rupture widths than shallower ones [77]. However, such behaviour is not clearly confirmed by earthquake observations and controversy remains, e.g. $[78,79]$. In the case of forced fluid circulation in a geothermal field, it is also possible that a reduction of differential stress due to pore pressure increase leads to reduced stress drop, as observed by Goertz-Allmann et al. [80]. Finally, the self-similarity of earthquakes characteristics, such as stress drop versus seismic moment, is still subject of debate, although several observations for both earthquakes and induced seismic events are consistent with constant stress drops for magnitudes ranging between 9 and -4, e.g. [81-83]. 


\subsection{Fluid-driven stress changes}

In geothermal fields, fault systems are the main targets of drilling, possibly for hydraulic stimulation and certainly for water circulation, since they promise to bring about high production rates that are needed for an economically efficient operation of the installation. Geothermal reservoirs are thus composed of fractures embedded in the rock matrix, both of which contain geothermal brine. Prior to geothermal operations, the underground is assumed to be in a stable steady state. Fluid injection, fluid production, and fluid circulation will perturb the in-situ stress field, mainly as a result of the variation of the pore pressure and locally also due to temperature changes. Physics-based models are, in theory, capable of predicting the associated stress changes. This provides a means to estimate whether the critical stress required to bring the rock to failure is reached. However, the models need to integrate proper coupling of fluid flow, heat transport, geomechanical, and geochemical processes relevant to induced seismicity in geothermal applications. In addition, they must have well-constrained model parameters as well as appropriate boundary and initial conditions that are calibrated against model-independent data. These coupled processes sketched in Figure 7 will be discussed in the following sections.

\section{[Recommended location of Figure 7, one or two columns]}

\subsubsection{Fluid flow}

Fluid flow is governed by the principle of mass balance and the continuity equation. In geothermal reservoirs, fluid flow can take place in the rock matrix or in faults and fractures. Flow in a porous rock matrix is described by Darcy's law $v=-k / \mu \cdot \nabla p$, where $v, k, \mu$, and $\nabla p$ denote the Darcy velocity, permeability, dynamic viscosity, and the pressure gradient, respectively. In a fractured rock, the flow rate is $Q=v \cdot a=-a \cdot k / \mu \cdot \nabla p$, where $v$ and a denote the linear fluid velocity and the fracture aperture, respectively. The permeability $k$ can also be approximated by $a^{2} / 12$, resulting in the so-called cubic law with $Q$ proportional to $a^{3}$ [84]. It represents the common approximation of fluid flow in fractures as Poiseuille flow between parallel plates. The hydraulic field in a fractured medium is thus strongly dependent on the fracture aperture. In nature, however, fractures have a rough inhomogeneous aperture, which decreases the effective fracture aperture and, thus, reduces flow [85]. If rough fractures are subject to shear, anisotropy of hydraulic conductivity is introduced [86].

Forced fluid flow in a fracture changes the fracture aperture by an elastic response $[87,88]$. As a result of the increasing fracture aperture, the available space for the fluid and the hydraulic conductivity increase considerably (see cubic law), which in turn reduces pore fluid pressure build-up. If, however, pore fluid pressure increases further, the failure criterion can be reached. A reduction of the effective minimum principal stress to the (negative) tensile strength of the rock will cause tensile fracturing (mode I failure) and development of new fractures. A relative increase of the shear stress to normal effective stress ratio can either reactivate favourably oriented existing fractures or create new ones by shearing (mode II failure). If shearing occurs on a pre-existing fracture, the fracture aperture will further increase through dilation. This process justifies the use of hydraulic shearing stimulations in EGS to improve reservoir permeability.

Different models can be used to describe the increase of fracture aperture by shearing. Most commonly, the models described by Barton et al. [89] and Willis-Richards et al. [90] are used. For granite, they were compared experimentally by Chen et al. [91]. They found them 
to generally perform equally well with regard to the tested rock samples and did not give any clear preference to either of these models. Hence, the hydraulic response of a reservoir to sudden fluid injection is characterized by a rapid increase in pressure also relatively far away from the injection source, if the fluid flow is fracture-dominated. With time, an equilibrium pressure level can develop between constant injection rate and enhancement of permeability. Finally, increases of injection rate are followed by small increases of pressure only, as the previous pressurization created additional permeability. Figure 8 illustrates the differences of the hydraulic responses of an injection well and of a reservoir under stimulation considering (a) a poroelastic model in a homogeneous effective medium with diffusional spreading of the pressure perturbation [92], and (b) a fracture mechanics model considering the interaction of pore pressure and the hydraulic properties of fractures [93]. These hydro-mechanical couplings were observed during geothermal well stimulations. In many EGS cases, they underlined dominance of fracture flow [32, 94-96].

\section{[Recommended location of Figure 8, on one column]}

\subsubsection{Heat transport}

Fluid circulation in geothermal systems generates temperature gradients. Hence, heat transport and conductive temperature changes must be considered as well. Temperature changes are driven by advection, conduction, and radiation, the latter being of no relevance to our application. Advective heat flow is coupled to mass transfer of fluids and, thus, dominant in rock fractures that serve as a heat exchanger. Conductive heat flow governed by Fourier's law is the ruling mechanism in an impermeable rock matrix. Under temperature gradients, several reservoir parameters can vary. For example, the fluid viscosity changes by an order of magnitude between $20^{\circ} \mathrm{C}$ and $100^{\circ} \mathrm{C}$, which can affect hydraulic fracture propagation, e.g. [97]. Furthermore, rock and fluids tend to expand or contract with temperature changes. As the thermal coefficient of volumetric expansion of water typically is five times larger than that of rock, temperature-induced changes of pore pressure are also strongly dependent on the rock permeability [98].

Thermal stresses can easily reach several MPa and are believed to be the primary source of induced seismicity e.g. in the vapour-dominated The Geysers geothermal field (Rutqvist and Oldenburg 2008). The quantification of thermal stresses, however, is extremely difficult, since they are highly dependent on the actual geometry of the underground heat exchanger, which remains largely unknown.

\subsubsection{Geomechanics}

The geomechanics is governed by force equilibrium and constitutive equations for the different rocks of the reservoir. Examples are Hooke's law for a rock matrix with elastic behaviour or other laws for more complex rock behaviour like plasticity and creep [88]. These laws relate displacement and strain (spatial derivatives of displacement) to stress.

Forced fluid injection, circulation, or production lead to variations of the pore fluid pressure, which, in turn, change the effective stress that possibly leads to the failure of the rock. But the fluid pressure variation also tends to change the volume of the rock matrix, including the pore space, and induces additional stress. These processes are described by the theory of 
poroelasticity [99-102], which couples pore fluid pressure and stress field. An analogous coupling exists between temperature and stress field [103], it is described by the theory of thermoelasticity [104]. To handle both couplings, they have to be unified to form the theory of thermo-poroelasticity. Analytical solutions exist for a few special cases [105-108]. For complex problems, however, numerical tools have to be used. These tools either solve the complex system of fully coupled differential equations, e.g. [109, 110], or rely on a solution scheme that couples sequentially, e.g. [111]. Besides this, several other coupling mechanisms exist in fractured reservoirs. Tsang [112] and Rutqvist and Stephansson [113] give comprehensive reviews of them.

Following shearing of rock, stresses are redistributed. Close to the fracture tips, stresses are built up, while around the perimeter, stresses are released. Analytical solutions that describe the displacement field induced by static dislocations were derived by Okada [114] for a homogeneous half-space and later extended for multi-layered elasticity and viscoelasticity by Wang et al. [115, 116] using a Green's function approach. Based on this approach, aftershock sequences following large earthquakes could be described by modelling static stress changes [117-119]. The influence of these co-seismic static stress changes during reservoir stimulation on induced seismicity is analysed in Schoenball et al. [31] and Catalli et al. [120]. Several numerical models use the redistribution of stress after failure of a slip patch to propagate failure to neighbouring slip patches and, thus, obtain rupture areas and, finally, seismic event magnitudes. The codes by Yamashita [121] and McClure and Horne [122] use static stress transfer from analytical solutions by Okada and a displacement discontinuity approach, respectively. Baisch et al. [123] use a generic block slider stress redistribution pattern.

However, there is considerable evidence of a large contribution of aseismic displacement to the total deformation induced during hydraulic stimulation of reservoirs, e.g. [124-128]. While the mechanism of these processes still is mostly unclear, the deformation is supposed to occur with slip velocities far below sonic velocities. To model these processes adequately, the rate- and state-dependent friction law can be used $[75,129]$. Such slow slip events with no classical seismic signal have also been observed in natural settings, and pore pressure changes within the seismic cycle seem to play a major role [130, 131].

\subsubsection{Geochemistry}

Only little progress has been achieved so far in modelling geochemical processes coupled to the thermo-hydro-mechanical processes in fractured reservoirs. This is probably related to the small importance these processes are supposed to have to induced seismicity, at least on a short time scale, but also to the complexity of the topic. Only two of the codes presented below model chemical processes in conjunction with thermal and hydraulic processes [132, 133], with the latter being also coupled to mechanical processes.

\subsection{Geomechanical-numerical models (GNMs)}

A previous review of simulators for geothermal reservoirs was presented by Hayashi et al. [134]. Since then, advancement in computer capacities has led to many codes that are capable of solving (fully) coupled geomechanical problems in 2D and 3D. Several codes are discussed below and summarised in Table 1. The list is far from being complete, but covers the main approaches available today. 
The primary results of the GNMs are, in most cases, the field variables of stress, strain, pore pressure, and temperature. To solve the numerical problem, initial and boundary conditions must be defined for reservoir temperature, porosity, permeability, pore pressure, saturation degree, and in-situ stress. The implemented constitutive laws allow modelling the transient stress source due to the man-made perturbations.

In order to derive from these results a seismic event distribution in time and space, the resulting stress field of the model is tested against an a priori chosen failure criterion. When failure is reached, an event is assigned a posteriori of the modelling process. Hence, most of the current GNMs do not simulate the seismic rupture as an implemented process. Consequently, the derived seismicity is model-dependent and several of its typical attributes may be unresolved (e.g. seismic event location, event magnitude and energy release, stress release and rupture dynamics). Nevertheless, the GNMs may theoretically link the operation parameters controlling the forced fluid circulation with characteristics of induced seismicity. The effects on the induced seismicity of varying stimulation scenarios may be tested, which includes changing injection rate, injection duration, cyclic injection, alternating injection/production cycles, e.g. [135-137].

\section{[Recommended location of Table 1, on two columns, landscape]}

Three groups of GNMs are distinguished: 1) Rock matrix-oriented models based on pore pressure diffusion without any feedback or secondary process modelled, 2) fracture-oriented models, and 3) all other models that do not belong clearly to the first two groups.

\subsubsection{Rock matrix-oriented models}

For the understanding of specific processes, it is worth keeping the models simple and avoiding the complexity involved in modelling a fractured reservoir. The models presented in this section consider fluid flow as a diffusional process in an equivalent 2D or 3D medium.

Shapiro et al. [138] proposed to fit the propagation of the front of the seismicity, which was induced during hydraulic stimulation at the KTB site (Germany), to the diffusion of a porepressure perturbation in an equivalent medium. A similar approach was applied to the cloud of microseismic events induced by the stimulation of GPK1 well at Soultz-sous-Forêts (France) [139]. The ellipsoidal shape of the cloud was interpreted to result from anisotropic diffusivity of the reservoir rock. Later, Shapiro et al. [140] generalised the previous work to invert for permeability in a heterogeneous reservoir. Rothert and Shapiro [141] used this description to model induced seismicity in a similar context. The volume of interest is filled with a randomly distributed criticality value that represents the perturbation of pore fluid pressure needed to reach failure. As the medium is assumed to be sub-critically stressed, critical pressures of nearly zero can exist. Pore fluid pressure is propagated by diffusion and no change of reservoir parameters (e.g. permeability) during stimulation is considered. The anisotropy of the permeability is estimated by means of fitting the model results to the observed elongated induced seismicity cloud. By construction, this model can estimate induced seismicity front propagation, but cannot yield other important seismicity attributes and physical justifications for the criticality values.

The approach by Schoenball et al. [142] is also based on the modelling of linear pore pressure diffusion. They use the commercial finite element package Abaqus to model the 
pore pressure changes due to fluid injection under a given tectonic load. The code solves the full set of poroelastic field equations with the assumption of homogeneous effective properties of a fractured rock mass. Effective stresses are evaluated on a regular grid for failure by a Coulomb criterion. Coupling of the spatio-temporal evolution of a cloud of induced seismicity with tectonic stresses is studied. They show that elongated seismic clouds may be also explained by an anisotropic in-situ stress field without the use of anisotropic diffusivity. Recent versions of Abaqus have a fully coupled solver for thermo-poroelastic elements.

\subsubsection{Fracture-oriented models}

This group of models simulates pore fluid propagation mainly (or solely) in a network of rock fractures. There is abundant evidence of fluid flow in EGS sites being dominated by fractures [143-146], which is why it should be taken into account by modelling. Several approaches to stochastic fracture network description have been proposed and are used by simulators presented below [90, 147].

Baisch et al. [123] model pore fluid pressure diffusion on a single 2D fault plane, the hydraulic properties of the rock matrix are ignored. The simulated fault is sub-divided into slip patches which are mechanically coupled to their neighbours by a block-spring model [148]. During injection, pressure diffusion is computed and the ratio of the shear stress to the effective normal stress is compared everywhere with the friction coefficient (Mohr-Coulomb failure criterion). Upon shearing of a slip patch, $90 \%$ of the acting stress are transferred to neighbouring slip patches according to a linear elastic stress transfer, which may lead to subsequent failure of these slip patches. Event magnitudes are calculated according to the accumulated area of connected patches slipping during the same time step. Following failure, permeability of the sheared slip patches is increased, but the storage coefficient is maintained constant and elastic opening of fractures is not considered. As the elastic opening of fractures is not considered in the code and the permeability only increases after shearing, the non-linear pressure dependency of increases of the injection rate is matched only partially by this model. However, the increase of magnitude with time and also after shut-in is reproduced and explained by the geometrical spreading of the pore pressure perturbation. The model also reproduces the Kaiser effect [149] as a developing zone of quiescence around the injection well.

Yamashita [121] models spreading of seismicity by fluid migration along a tectonic fault rather than a geothermal reservoir. The $2 \mathrm{D}$ fault zone of varying thickness is embedded in a $3 \mathrm{D}$ poroelastic matrix. He assumes slip patches to interact with each other after slippage by static stress changes derived from analytical solutions by Okada [114]. Using this scheme to model and propagate failure, he is able to derive Gutenberg-Richter relations from heterogeneously distributed fault zone properties.

FRIP, an early reservoir simulator for hot dry rock systems, was developed by Cundall [150] and Pine and Batchelor [151]. It uses a 2D finite difference approach with a network of rectangular fractures located between elastic blocks. Joint apertures change elastically and by shearing.

The FRACAS code [152-154] is based on a 3D discrete fracture network (DFN) approach. The network consists of 2D meshed fractures with a power law size distribution. For calculation of fluid flow, the network is reduced to $1 \mathrm{D}$ equivalent flow channels obeying the cubic flow law. Permeability enhancement is obtained from shearing following fulfilment of 
the Coulomb criterion and elastic opening according to Barton et al. [89]. Fully coupled heat transport and heat extraction are modelled at the fracture surfaces and in the matrix volume. The magnitude-frequency distribution for shearing events, defined by the $b$-value, is directly inherited from the fractal size distribution of the fractures in the DFN.

FRACSIM-3D [90, 155] is used as a prototype for many of the codes presented in this review. A 3D stochastic fracture network with elastic opening and shearing, including dilation upon hydraulic pressurization, is implemented in this code. Effective hydraulic properties from the fracture mechanics module are sequentially computed and mapped to the finite differences mesh. To reduce the model volume yet applying realistic hydraulic boundary conditions, a larger hydraulic sphere containing the model volume is considered. Fluid fluxes from the model volume to the outer sphere are applied as boundary conditions. Heat extraction is calculated under the assumption of instantaneous thermal equilibrium. The code has been modified to take into account the water/rock chemical interaction [133, 156].

The DFN code HEX-S [93] is an advancement of the finite element code FRACTure [157]. It uses a mixed 3D DFN, consisting of deterministic fractures known from logging of wellbores and stochastic fractures in the geothermal reservoir. FRACTure uses 1D and 2D elements in a $3 D$ model to simulate flow in fractures and wellbores. It is capable of coupled thermohydro-mechanical modelling and was later coupled with the geochemical module CHEMTOUGH for thermal-hydraulic-chemical modelling [132]. In the model of Kohl and Mégel [93], pre-existing fractures are partitioned into slip patches. For each time step, a shear criterion is evaluated separately on each slip patch. It shears or does not shear independently of any neighbouring slip patches. Thus, seismic event magnitudes are not obtained by this model, but multiple shearing and the propagation of shearing of one fracture over several time steps are considered.

McClure and Horne [158] model induced seismicity by a two-dimensional DFN approach. Fluid is injected into a single fracture and propagates through the network according to the cubic law. Similar to Baisch et al. [123] and Kohl and Mégel [93], the fractures are partitioned into smaller slip patches. They calculate stresses transferred by fracture propagation on neighbouring slip patches using a boundary element method. Summation over slipping areas of one time step enables them to model magnitudes of shearing events. McClure and Horne [129] present an approach to modelling the fracture slipping behaviour according to a rateand-state friction law, which allows them modelling and predicting aseismic slip, which is defined as shearing at low slip velocity.

Koh et al. [110] use the fully coupled thermo-poroelastic model from Ghassemi et al. [159] to simulate fracture aperture responses to changes in stress, fluid pressures, and temperature. The discretized fracture elements of their 2D fracture network are coupled to normal and shear stresses through the Willis-Richards et al. [90] model for elastic opening and shearing.

Ghassemi et al. [109] developed a 3D coupled heat extraction, thermal stress, elastic displacement discontinuity model for the analysis of thermomechanical interaction on a single fracture during production. They make use of a Green's function approach to modelling the problem without discretization. The slipping fracture is modelled using a boundary element method, the surrounding matrix is hydraulically impermeable and no poromechanical effects are considered. 


\subsubsection{Alternative models of rock}

Yoon et al. [160] used a fracture mechanics approach to simulating the process of dynamic fracture generation and frictional failure of an implemented discrete fracture network using the discrete element method of the PFC code [161]. A hydro-mechanical coupling scheme is implemented that allows for fluid flow-driven bond breakages in mode I (tensile) and mode II (shear) failure according to the Mohr-Coulomb criterion. Bond breakage results in seismic energy radiation, from which seismic source information is retrieved, e.g. magnitude and focal mechanisms of mode I [162, 163] and mode II fractures [137, 160]. Along the model boundaries, a zone with high viscous damping properties is used to model energy absorption and to exclude side effects on bond breakages coming from reflected kinetic seismic wave energy at the model boundaries. The onset of tensile and shear fractures of intact rock (enhanced parallel bonds) and pre-existing joints (smooth joint contacts) are governed by the Mohr-Coulomb failure criterion. Fracture breakdown pressure is estimated using the Haimson-Fairhurst equation [54]. The model output is the stress and strain field, pore pressure changes (and temperature, if needed) and, in particular, a synthetic catalogue of induced events with location and magnitude distribution as well as the failure type of the event.

FLAC3D [164] is a finite-difference geomechanical-numerical modelling code for advanced geotechnical analysis of soil, rock, and structural support in three dimensions. It applies a continuum analysis. Wassing et al. [165] implemented in FLAC3D the seismic behaviour of a single 2D fault using a ubiquitous joint model in all the fracture cells and adapting the fracture permeability based on its actual tensile and shear opening behaviour. The sub-surface geometry and the pressure diffusion principle are comparable to those proposed by Baisch et al. [123]. However, the stress redistribution follows a physics-based model rather than the intuitive representation of the geomechanics and calibrated engineering correlations of the block-spring model. This model can predict pore pressure (Figure 9), seismicity locations, and seismic moments.

\section{[Recommended location of Figure 9]}

TOUGH-FLAC [111] is a multi-purpose code for porous materials with applications extending from nuclear waste repositories to underground storage of $\mathrm{CO}_{2}$ and multi-phase geothermal reservoirs [166]. It sequentially couples the geomechanical code FLAC3D [164] with the multi-phase flow and heat transport code TOUGH2 [167]. Jeanne et al. [168] simulate the geothermal reservoir by an equivalent continuum with implicit representation of fractures and by explicit description of identified shear zones which will have different hydraulic and mechanical properties. A Mohr-Coulomb failure criterion is applied and the medium is assumed to be critically stressed to compute the relative variation of the maximum and minimum effective stresses necessary to induce shear. This microseismic potential, however, does not provide any real seismic event attribute, but a hint regarding the possible spatial and temporal distribution of induced seismicity.

Angus et al. [169] model microseismicity from reservoir production by coupling the commercial geomechanical solver ELFEN with the fluid-flow simulator MORE. The geomechanical part is based on the so-called SR3 constitutive model to simulate the complex behaviour of compacting sandstone and shale, including elastic anisotropy, rate 
dependency, and creep [170]. According to this model, point failure is modelled together with the stress drop and the earthquake failure mechanisms are obtained from analysis of preand post-failure effective stress tensors [171, 172], similarly to Hazzard and Young [162]. However, rupture length and slip to deduce actual magnitudes cannot be obtained from this approach.

\subsubsection{Bridging deterministic and probabilistic approaches}

As mentioned earlier, the GNMs give either stress and pore pressure changes as a result and an a posteriori-derived seismic event catalogue (mostly without magnitude distribution, but with event location and time only) or a full synthetic catalogue of induced events (mostly with magnitude distribution, time, and location). To use this variety of model outputs, Hakimhashemi et al. [43] propose a general workflow for forward induced seismic hazard assessment (FISHA), which estimates from these results the change of seismicity rate as a function of time and space. This workflow has a predictive power, as it can test which physical parameter has the largest impact on the increase of the seismicity rate. Hakimhashemi et al. [43] apply the FISHA workflow using a synthetic catalogue of seismic events, including occurrence time, location, magnitude, and focal mechanisms induced by water injection, from Yoon et al. [173], as was described in section 4.4.3. Using Eq. (1), they can compute event occurrence rate changes during injection and discuss possible injection scenarios to minimize the number of events, their maximum magnitude, and the total seismic energy release.

A second example of the FISHA workflow is presented in Hakimhashemi et al. [174]. Here, they use the pore pressure changes of a GNM of the Soultz-sous-Forêts EGS field from Kohl and Mégel [93]. To convert the stress change field into temporal change of seismicity rate, they use the rate and state model of Dieterich [76]. Seismicity is described by its occurrence rate and location, but magnitudes are not available. The critical part of the FISHA workflow is the validation of the generated synthetic seismic catalogue for a given site and the translation of stress and/or pore pressure changes using the rate and state law. The latter is probably not perfectly appropriate, but can be replaced by any other translator to apply the FISHA workflow.

\section{HYBRID FORECASTING APPROACHES}

Conceptually, we define the hybrid approach as a combination of physics-based models with statistical models. The hybrid approach is attractive, because it can benefit from the advantages of both other approaches, while minimizing their inconveniences. In the current state of development of the hybrid approach, GNMs are used to quantify the stress perturbation induced by the geothermal activity - essentially massive hydraulic stimulation and to define a failure criterion. Then, the probability of the energy released by a seismic event is estimated using statistics-based models.

Shapiro et al. [175] propose a method to estimate the probability of a given-magnitude event induced by fluid injection. For several massive injection operations, they note that the cumulative number of seismic events induced above a given magnitude is proportional to the time elapsed since the beginning of the injection, with the injection rate being constant. They also show that the event rate is proportional to the injected fluid volume [176]. Following the work of Shapiro et al. [140] and Rothert and Shapiro [141], the pore pressure change is described as a diffusive process which occurs in a medium with random distribution of pre- 
existing, not interacting crack seeds (with concentration $K_{c}$ ). A seismic event will occur on a seed when the pore pressure increase will reach a random value distributed in a given range provided by observations and bounded by the $C_{\max }$ value [177]. Applying a constant injection rate with constant fluid properties, this model predicts that the cumulative number of events, $N$, at elapsed time, $t$, increases linearly with the injected volume $V(t): N(t)=K_{c} \cdot V(t) / C_{\max } \cdot S$, where $S$ denotes the storage coefficient and $C_{\max }$ denotes the maximum value needed to bring a seed to failure. In combination with the seismic event magnitude distribution inherited from the Gutenberg-Richter law, it gives the probability of the number of events, $P_{N}$, at time $t$ larger than magnitude $M_{m}$ :

$$
P_{N}\left(t, M_{m}\right)=\frac{K_{c} V(t)}{C_{\max } S} 10^{\left(a-b M_{m}\right)}
$$

where $a$ and $b$ are the coefficients of the Gutenberg-Richter law. This approach can explain the occurrence of larger-magnitude events at the end of massive fluid injections, but is not suitable at this stage for prediction during or after shut-in of the injection well. Furthermore, it does not allow for the lowering of the pore pressure and, thus, long-term production, shut-in phase and cyclic injections cannot be investigated.

Dinske and Shapiro [178] analyse the time distribution of the number of events larger than magnitude $M_{m}$, for six different injection operations (both in geothermal and oil and gas fields). They look for any typical values of the "seismogenic index", $\Sigma=a-\log \left(\left(C_{\max } \cdot S\right) / K_{c}\right)$, which may quantify the propensity of the formation to induce seismicity under injection. They observe that the larger seismogenic indices correspond to geothermal fields which are, thus, likely to produce larger seismic events, while the lower values hold for oil and gas fields. This model is applied to very different data sets with regard to magnitude ranges of induced seismicity, geological and tectonic settings of the reservoirs, field operations, and processing techniques. This may cause bias in the results and explain part of the variations observed by Dinske and Shapiro [178] between seismogenic indices computed for similar fields. Further experience is required to assess the capabilities of an initially estimated "seismogenic index" to forecast induced seismicity in geothermal reservoirs and to use it as a key parameter. The addition of the modified Omori's type law to the model for the period following the injection (see section 3.2) allows for the prediction of the seismicity during shut-in [179]. Hence, this additional feature, together with the a priori Gutenberg-Richter distribution, combines a pressure diffusion model with a statistical seismicity approach.

To model a hydraulic stimulation of a deep geothermal field, Goertz-Allmann \& Wiemer [180] also use a pressure diffusion model in a hydraulically homogeneous and isotropic medium, but introduce different failure conditions. They consider a Mohr-Coulomb failure criterion and define the critical state of any point in the reservoir based on random normal perturbation of the minimum and maximum effective stresses. Prior to fluid injection, the geomaterial is in a stable state, but as soon as fluid injection starts, pore pressure can vary to reach the failure line. The parameters describing the physical model are consistent with the values obtained for this field or were derived from calibration. The physical parameters were held fixed during modelling. The magnitude of the seismic events is obtained from random draw on a Gutenberg-Richter law, which was calibrated using the induced seismicity at Basel and assuming proportionality between the $b$-value and the differential stress value $\left(\sigma_{1}-\sigma_{3}\right)$. This method allows forecasting location, magnitude, stress-drop, and amount of seismicity over time. It was applied to the Basel (Switzerland) EGS stimulation and was able to reproduce the observation of increasing stress drops and decreasing b-values as a function of the offset 
from the injection well. Additionally, the probability of larger-magnitude events after well shutin increases as well as the probability of occurring further away from the injection point.

Gischig and Wiemer [44] further develop the previous approach by introducing a non-linear pore pressure diffusion model coupled to irreversible permeability enhancement. The initial hydraulic parameters of the diffusion model are first calibrated against a pre-stimulation test. Then, the pressure field is used as input in the model described by Goertz-Allmann \& Wiemer [180]. As seismicity occurs during the main stimulation, the dynamic pressure diffusion model and the failure criteria model can be calibrated. Both calibrations can be done independently thanks to the decoupling of pressure field modelling and seismicity modelling. As a result, Gischig and Wiemer [44] are able to reproduce the hydraulic behaviour during stimulation as well as the time evolution of the seismicity and its frequencymagnitude distribution. They can also simulate real-time application of their model to estimate the seismic hazard in the course of the stimulation. Finally, they provide forecasts for alternative injection scenarios relating to the seismic hazard.

\section{APPLICABILITY AND LIMITATIONS OF CURRENT APPROACHES}

As shown, several models have been developed and applied to geothermal fields to reproduce induced seismicity or to forecast it. Statistical, physics-based, or hybrid approaches can generate synthetic catalogues. However, the description of the seismic events may be variable and for few physics-based models, it may not yet be suitable to feed a PISHA (e.g. event magnitude missing).

The statistical seismicity approach is very attractive, because it can be implemented easily for real-time analysis and forecast of induced seismicity during massive water injection, especially EGS stimulations. It cannot, however, propose operational reaction schemes to efficiently decrease the probability of forecasted large-magnitude events. By construction, physical links between the phenomena at the origin of seismicity and the seismicity catalogue are missing. Only physics-based approaches and extended hybrid models can provide for a prior understanding of the natural and operational parameters at the origin of the seismicity.

All statistical seismicity-based models relevant to geothermal applications have been developed and trained on EGS stimulations, which are the most seismogenic operations in geothermal fields and which can induce seismic events of economic relevance [16]. In such cases, they benefit from the vast amount of data needed for statistical analyses. It would be of interest to test the capabilities of these models during other typical geothermal operations. At the sites of Landau or Soultz-sous-Forêts, circulation operations under low pressure and flow rates are characterized by a low induced seismic event rate, but outside these conditions, noticeable if not felt seismic events can still occur, e.g. [181]. For these periods, the data availability to feed the statistics may be limited. Besides, the reliability of statistical seismicity-based models calibrated against day-long stimulations and applied to circulation periods lasting several months might be questioned.

In a way, this also applies to the physics-based models: they have been tested on seismicity induced during EGS stimulations, where the hydro-mechanical (sequential) coupling is assumed to be dominating. However, in deep (below $3.5 \mathrm{~km}$ depth) hydrothermal systems, where no hydraulic stimulation is required, seismicity of around 2 in magnitude can be 
induced by circulation [182]. The usually high permeability of such systems, the high fluid circulation rates, and the small overpressures applied to re-inject the fluids suggest that the major physico-chemical processes taking place during long-term circulations are different from those happening during short-term stimulations. Lacking seismic monitoring of these hydrothermal fields prevents any good understanding of the underlying phenomena. However, thermal and geochemical effects most likely play a major role. Temperature variations will affect hydraulic parameters, such as the fluid viscosity, but also deform the rock mass, thus requiring the application of thermoelasticity or thermo-poroelasticity theories. Besides, the history of the fluid-rock interaction and the corresponding alteration processes for a given rock type will affect the fluid path and the behaviour of the associated fracture surfaces. For example, weaker clay-filled fractures are likely to shear in a mode other than fresh rough fracture surfaces. Such observation is made on a large scale at the San Andreas Fault which exhibits both creeping and rupture zones [183, 184].

In addition to the difficulty of prioritizing physico-chemical processes within specific processes, basic assumptions limit the models. For example, the implementation of friction laws in numerical modelling is mostly limited to exceeding static friction on a fault plane. $A$ few codes include a strain-dependent friction coefficient (static-dynamic friction coefficient). A step even further would be to implement rate- and state-dependent friction models to understand the dynamic behaviour of the rock during seismic events [129, 185]. Fully comprehensive physics-based models would be inoperable and not represent the most significant processes they are meant for. Hence, a strong trade-off is made between thorough physical description and physics-based modelling. Only experience and case studies can help balance both features.

The initial parameters describing the geothermal reservoir properties have to be estimated to apply physics-based models. This can be achieved for several of them by using rock sample measurements and in-situ measurements. Yet, the question of the relevance of parameter upscaling arises. Dynamic parameters also need to be properly estimated. History matching with field observations can be used for calibration. Typically, the hydraulic response of wells subject to stimulation is used, e.g. [93, 152, 158], and/or specific seismic response characteristics of the reservoir are applied, e.g. [93, 177]. The latter calibration requires a catalogue of induced seismicity. The calibration process, however, does not guarantee that the chosen GNM is the best representative of the real behaviour. As an example, Kohl and Mégel [93] use a DFN and the Coulomb criterion to incorporate shear slip and jacking on the fractures. This approach is suitable for modelling high pore pressure gradients in the reservoir. The pressure at observation wells will differ according to the connectivity of the well to the DFN. Rothert and Shapiro [177] use an effective medium approach and model the propagation of the pore pressure perturbation by linear diffusion; no actual hydro-mechanical feedback process (i.e. shearing or jacking) is modelled. Failure occurs, if pore pressure exceeds an a priori given value of criticality. Consequently, both models use a very different approach and obtain fundamentally different distributions of pore fluid pressure (Figure 8). However, both models can be tuned to match seismic response characteristics observed during massive injection operations. As another example, the front of induced seismicity can develop elliptically during stimulation of the geothermal reservoir as a result of anisotropic hydraulic permeability [138, 139] or an anisotropic stress tensor [142]. It is not possible to distinguish between these two types of anisotropy based on the seismicity alone. These examples illustrate that a model is good as long as it can reproduce the observables. Therefore, it is crucial to acquire and calibrate against as many observables as possible. 
Only then are as realistic as possible models of induced seismicity obtained. Robust models applied to EGS stimulation should be able to reproduce, even in a probabilistic sense, all primary seismicity characteristics (location, time, magnitude, stress drop, focal mechanisms) and secondary ones (b-value or spatial distribution), but also pressure, flow rate, and temperature variations at wells. Once calibrated, the GNMs can understand in advance the influence of underlying natural and operational parameters on induced seismicity, so that it is possible to adapt exploration or exploitation strategies in addition to the real-time application of mitigation strategies.

Model calibration, however, removes neither the a priori uncertainties of all input parameters, nor the a posteriori uncertainties of the results. Random variation of the reservoir parameters within their uncertainty domain may reproduce aleatoric uncertainties within the results; unfortunately, CPU time still is too long. Alternatively, new concepts may be developed to reduce uncertainties of structural data in 3D geological inversions, for example [186]. Computational restrictions are also encountered, if several GNMs would be used in parallel to prevent epistemic uncertainties (as in logic tree approaches). These difficulties explain why GNMs provide deterministic catalogues of induced seismicity and not probabilistic ones.

Three time domains are relevant to induced seismicity forecasting approaches: 1) the rock forming geological timescale, 2) the hours/days/years of operations, and 3) the seconds of the rupture process. All models applied to induced seismicity in geothermal fields consider the anthropogenic effects after hours or days of operations in a transient way. It would be reasonable in the future to consider or not oversimplify the rupture process lasting for a shorter period. Similarly, the incorporation of variations of the geomaterial characteristics is needed on a geological timescale and possibly on the scale of the field exploitation.

It is necessary to benchmark the different models on the basis of several data sets. Only then, will it be possible to quantify the performance, robustness, and prediction capabilities of the associated numerical codes. Besides, this should help to identify the processes most relevant to induced seismicity. Similar benchmarking efforts have been made, for example, regarding the different constitutive behaviours of rock salt [187] and for sandbox experiments with forced compression and extension [188]. Especially the latter showed a remarkable variation of the results of both the numerical models and the different sandbox experiments.

\section{CONCLUSION}

Induced seismicity is associated with deep geothermal development, where fluids circulate in the reservoir. Although this issue has been well-known for 30 years, geophysical interest in this issue increased considerably with the development of EGS, as reflected by the quantity of available information. The general concerns about induced seismicity relate to projects developed in populated area and require models that are able to forecast seismicity.

The initial models which assumed that suspending geothermal operations could instantaneously stop, minimize or reduce the related induced seismicity have failed. Induced seismicity must be considered as a time-dependent process. This component is very clearly integrated into the statistical seismicity approach which, however, lacks any physical explanation of the involved processes. Therefore, it is unable to propose preventive measures. Physics-based models are appropriate for that purpose, but require very good characterization of the geothermal reservoir to select the most relevant physical processes 
which would lead to rock failure and seismicity. Hybrid models can combine the advantages of both approaches. Physics-based models provide the link between induced seismicity and geothermal operations, while the statistical seismicity models provide the frame for uncertainty quantification and integration of the results into a probabilistic induced seismic hazard assessment.

The quantitative understanding and forecasting of induced seismicity is a challenging and complex matter which is at its beginning. Efforts should continue in several directions. There is a need for new approaches that account for the geological uncertainties of the reservoir structure, the mechanical, thermal, hydraulic, and chemical parameters, and the coupled processes. State-of-the-art scientific computing concepts and true high-performance computing are urgently needed to handle the true complexity of the underground.

It is scientific standard that models are accurately calibrated and sensitivities are determined. The larger the range of applications is, the more trustworthy is a model. Hence, efforts to obtain geophysical and geochemical measurements on a long-term basis and at several locations and to capture the processes that are driving earthquakes in geothermal fields are valuable. In-situ laboratories, intensively monitored fields, and geothermal databases can contribute to the effort of increasing the number of observables. Modelling can help to identify the values of different sources of information.

Only an integration of all current research and development efforts into measuring, monitoring, modelling, and matching will allow for the successful forecasting of induced seismicity in geothermal fields. Such an integration is the prerequisite for making this highpotential renewable energy resource sustainable.

\section{ACKNOWLEDGEMENTS}

The authors would like to thank the EnBW Energie Baden-Württemberg AG, the FP7 project GEISER of the European Commission (grant agreement no. 241321), and the Department of Energy's Geothermal Technologies Program (Award Number DE-EE0002756-002) for financial support. The authors are also grateful to T. Kölbel (EnBW) for fruitful comments on the paper and to M. Schroeder (KIT) for English editing.

\section{REFERENCES}

[1] IEA. Technology Roadmap, Geothermal Heat and Power. In: Johnston A, Smith M, editors.: International Energy Agency; 2011. p. 52.

[2] Tester JW, Anderson BJ, Batchelor AS, Blackwell DD, DiPippo R, Drake EM, et al. The Future of Geothermal Energy: Impact of Enhanced Geothermal Systems (EGS) on the United States in the 21st Century. Idaho Falls: Massachusetts Institute of Technology; 2006.

[3] Bertani R. Geothermal power generation in the world 2005-2010 update report. World Geothermal Congress. Bali, Indonesia, 25-29 April 2010.

[4] Marks SM, Ludwin RS, Louie KB, Bufe CG. Seismic monitoring at the Geysers geothermal field, California. 1978. p. 30.

[5] Aki K, Fehler M, Aamodt RL, Albright JN, Potter RM, Pearson CM, et al. Interpretation of seismic data from hydraulic fracturing experiments at the Fenton Hill, New Mexico, Hot Dry Rock geothermal site. Journal of Geophysical Research. 1982;87:936-44. 
[6] Deichmann N, Giardini D. Earthquakes induced by the stimulation of an enhanced geothermal system below Basel (Switzerland). Seismological Research Letters. 2009;80:784-98.

[7] Baisch S, Carbon D, Dannwolf U, Delacou B, Devaux M, Dunand F, et al. Deep Heat Mining Basel: Seismic risk analysis. SERIANEX: Report from Department für Wirtschaft, Soziales und Umwelt des Kanton Basel-Stadt. Amt für Umwelt und Energie; 2009.

[8] Bönnemann C, Schmidt B, Ritter J, Gestermann N, Plenefisch T, Wegler U, et al. Das seismische Ereignis bei Landau vom 15. August 2009. Abschlussbericht der Expertengruppe "Seismisches Risiko bei hydrothermaler Geothermie". Hannover2010. p. 55.

[9] Edwards B, Kraft T, Cauzzi C, Kästli P, Wiemer S. Seismic monitoring and analysis of deep geothermal projects in St Gallen and Basel, Switzerland. Geophysical Journal International. 2015;201:1022-39.

[10] Trifu Cl. Special issue: The mechanism of induced seismicity. Pure and Applied Geophysics. 2002;159.

[11] Trifu Cl. Special issue: Monitoring induced seismicity. Pure and Applied Geophysics. 2010;167.

[12] Grünthal G. Induced seismicity related to geothermal projects versus natural tectonic earthquakes and other types of induced seismic events in Central Europe. Geothermics. 2014;52:2235.

[13] Healy JH, Rubey WW, Griggs DT, Raleigh CB. The Denver earthquakes. Science. 1968;161:130110.

[14] Ellsworth WL. Injection-Induced Earthquakes. Science. 2013;341.

[15] Majer EL, Baria R, Stark M, Oates S, Bommer J, Smith B, et al. Induced seismicity associated with Enhanced Geothermal Systems. Geothermics. 2007;36:185-222.

[16] Evans KF, Zappone A, Kraft T, Deichmann N, Moia F. A survey of the induced seismic responses to fluid injection in geothermal and CO2 reservoirs in Europe. Geothermics. 2012;41:30-54.

[17] National Research Council. Induced Seismicity Potential in Energy Technologies. Washington, DC: The National Academies Press; 2013.

[18] Majer EL, Baria R, Stark M. Protocol for induced seismicity associated with enhanced geothermal systems. International Energy Agency - Geothermal Implementing Agreement; 2008.

[19] Majer E, Nelson J, Robertson-Tait A, Savy J, Wong I. Protocol for addressing induced seismicity associated with enhanced geothermal systems. U.S. Department of Energy; 2012. p. 52.

[20] Baisch S, Fritschen R, Groos JC, Kraft T, Plenefisch T, Ritter J, et al. Richtlinie GtV 1101: Seismizität bei Geothermieprojekten, Blatt 1 "Seismische Überwachung" GtV-Bundesverbandes Geothermie e.V.; 2011. p. 1-8.

[21] GEISER. Geothermal Engineering Integrating Mitigation of Induced Seismicity in Reservoirs, Final Reports. 2013. Available from: (http://www.geiserfp7.fr/ReferenceDocuments/Pages/ReferenceDocuments.aspx).

[22] Genter A, Evans K, Cuenot N, Fritsch D, Sanjuan B. Contribution of the exploration of deep crystalline fractured reservoir of Soultz to the knowledge of enhanced geothermal systems (EGS). Comptes Rendus Geoscience. 2010;342:502-16.

[23] Cornell CA. Engineering seismic risk analysis. Bulletin of the Seismological Society of America. 1968;58:1583-\&.

[24] Grünthal G, Stromeyer D, Wahlström R. Harmonization check of Mw within the central, northern, and northwestern European earthquake catalogue (CENEC). Journal of Seismology. 2009;13:613-32.

[25] Grünthal G, Wahlström R, Stromeyer D. The unified catalogue of earthquakes in central, northern, and northwestern Europe (CENEC) - updated and expanded to the last millennium. Journal of Seismology. 2009;13:517-41.

[26] Boore DM, Atkinson GM. Ground-motion prediction equations for the average horizontal component of PGA, PGV, and 5\%-damped PSA at spectral periods between $0.01 \mathrm{~s}$ and $10.0 \mathrm{~s}$. Earthquake Spectra. 2008;24:99-138.

[27] Stromeyer D, Grünthal G. Attenuation relationship of macroseismic intensities in Central Europe. Bulletin of the Seismological Society of America. 2009;99:554-65. 
[28] Douglas J, Edwards B, Convertito V, Sharma N, Tramelli A, Kraaijpoel D, et al. Predicting ground motion from induced earthquakes in geothermal areas. Bulletin of the Seismological Society of America. 2013;103:1875-97.

[29] Bommer JJ, Oates S, Cepeda JM, Lindholm C, Bird J, Torres R, et al. Control of hazard due to seismicity induced by a hot fractured rock geothermal project. Engineering Geology. 2006;83:287306.

[30] Langenbruch C, Dinske C, Shapiro SA. Inter event times of fluid induced earthquakes suggest their Poisson nature. Geophysical Research Letters. 2011;38:L21302.

[31] Schoenball M, Baujard C, Kohl T, Dorbath L. The role of triggering by static stress transfer during geothermal reservoir stimulation. Journal of Geophysical Research. 2012;117:B09307.

[32] Häring MO, Schanz U, Ladner F, Dyer BC. Characterisation of the Basel 1 enhanced geothermal system. Geothermics. 2008;37:469-95.

[33] Charléty J, Cuenot N, Dorbath L, Dorbath C, Haessler H, Frogneux M. Large earthquakes during hydraulic stimulations at the geothermal site of Soultz-sous-Forêts. International Journal of Rock Mechanics and Mining Sciences. 2007;44:1091-105.

[34] Utsu T. Statistical features of seismicity. In: Lee WHK, Kanamori H, Jennings PC, Kisslinger C, editors. International Handbook of Earthquake and Engineering Seismology: Academic Press; 2002. p. 719-32.

[35] Bachmann CE, Wiemer S, Woessner J, Hainzl S. Statistical analysis of the induced Basel 2006 earthquake sequence: introducing a probability-based monitoring approach for Enhanced Geothermal Systems. Geophysical Journal International. 2011;186:793-807.

[36] Gutenberg B, Richter CF. Earthquake magnitude, intensity, energy, and acceleration: (Second paper). Bulletin of the Seismological Society of America. 1956;46:105-45.

[37] Ogata Y. Seismicity Analysis through Point-process Modeling: A Review. Pure and Applied Geophysics. 1999;155:471-507.

[38] Utsu T. A statistical study on the occurrence of aftershocks. Geophysics Magazine. 1961;30:521605.

[39] Reasenberg PA, Jones LM. Earthquake hazard after a mainshock in California. Science. 1989;243:1173-6.

[40] Ogata Y. Statistical Models for Earthquake Occurrences and Residual Analysis for Point Processes. Journal of the American Statistical Association. 1988;83:9-27.

[41] Wiemer S, Giardini D, Fäh D, Deichmann N, Sellami S. Probabilistic seismic hazard assessment of Switzerland: best estimates and uncertainties. Journal of Seismology. 2009;13:449-78.

[42] Mena B, Wiemer S, Bachmann C. Building Robust Models to Forecast the Induced Seismicity Related to Geothermal Reservoir Enhancement. Bulletin of the Seismological Society of America. 2013;103:383-93.

[43] Hakimhashemi AH, Yoon JS, Heidbach O, Zang A, Grünthal G. FISHA - Forward induced seismic hazard assessment application to synthetic seismicity catalog generated by hydraulic stimulation modeling. 38th Workshop on Geothermal Reservoir Engineering. Stanford University, Stanford, California, Feb. 11-13 2013.

[44] Gischig VS, Wiemer S. A stochastic model for induced seismicity based on non-linear pressure diffusion and irreversible permeability enhancement. Geophysical Journal International. 2013;194:1229-49.

[45] McGarr A, Simpson DW. Keynote lecture: a broad look at induced and triggered seismicity In: Gibowicz SJ, Lasocki, S., editor. Rockbursts and seismicity in mines Proceedings of the 4th International Symposium on Rockbursts and Seismicity in Mines Poland, 11-14 August 1997. Rotterdam: A. A. Balkema Press; 1997. p. 385-96.

[46] Dahm T, Becker D, Bischoff M, Cesca S, Dost B, Fritschen R, et al. Recommendation for the discrimination of human-related and natural seismicity. Journal of Seismology. 2013;17:197-202.

[47] Heidbach O, Reinecker J, Tingay M, Müller B, Sperner B, Fuchs K, et al. Plate boundary forces are not enough: Second- and third-order stress patterns highlighted in the World Stress Map database. Tectonics. 2007;26:TC6014. 
[48] Cloetingh S, van Wees JD, Ziegler PA, Lenkey L, Beekman F, Tesauro M, et al. Lithosphere tectonics and thermo-mechanical properties: An integrated modelling approach for Enhanced Geothermal Systems exploration in Europe. Earth-Science Reviews. 2010;102:159-206.

[49] Heidbach O, Tingay M, Barth A, Reinecker J, Kurfeß D, Müller B. The World Stress Map database release 2008. 2008. Available from.

[50] Zang A, Stephansson O, Heidbach O, Janouschkowetz S. World Stress Map Database as a Resource for Rock Mechanics and Rock Engineering. Geotechnical and Geological Engineering. 2012;30:625-46.

[51] Meixner J, Schill E, Gaucher E, Kohl T. Inferring the in situ stress regime in deep sediments: an example from the Bruchsal geothermal site. Geothermal Energy. 2014;2:7.

[52] Schmitt DR, Currie CA, Zhang L. Crustal stress determination from boreholes and rock cores: Fundamental principles. Tectonophysics. 2012;580:1-26.

[53] Zoback MD. Reservoir geomechanics. Cambridge: Cambridge University Press; 2010.

[54] Zang A, Stephansson O. Stress field of the Earth's crust. Dordrecht: Springer Science \& Business Media B.V.; 2010.

[55] Haimson B, Bobet A. Introduction to Suggested Methods for Failure Criteria. Rock Mechanics and Rock Engineering. 2012:1-2.

[56] Mohr O. Welche Umstände bedingen die Elastizitätsgrenze und den Bruch eines Materials? [What are the conditions for the elastic limit and the fracturing of a material?]. Zeitschrift des Vereins Deutscher Ingenieure. 1900;44:1524.

[57] Labuz J, Zang A. Mohr-Coulomb Failure Criterion. Rock Mechanics and Rock Engineering. 2012:15.

[58] Byerlee J. Friction of rocks. Pure and Applied Geophysics. 1978;116:615-26.

[59] Worum G, van Wees J-D, Bada G, van Balen RT, Cloetingh S, Pagnier H. Slip tendency analysis as a tool to constrain fault reactivation: A numerical approach applied to three-dimensional fault models in the Roer Valley rift system (southeast Netherlands). Journal of Geophysical Research. 2004;109:B02401.

[60] Ziegler PA, Cloetingh S, van Wees JD. Dynamics of intra-plate compressional deformation: The Alpine foreland and other examples. Tectonophysics. 1995;252:7-59.

[61] da Fontoura S. Lade and Modified Lade 3D Rock Strength Criteria. Rock Mechanics and Rock Engineering. 2012:1-6.

[62] Alejano L, Bobet A. Drucker-Prager Criterion. Rock Mechanics and Rock Engineering. 2012:1-5.

[63] Eberhardt E. The Hoek-Brown Failure Criterion. Rock Mechanics and Rock Engineering. 2012:1-8.

[64] Priest S. Three-Dimensional Failure Criteria Based on the Hoek-Brown Criterion. Rock Mechanics and Rock Engineering. 2012:1-5.

[65] Benz T, Schwab R. A quantitative comparison of six rock failure criteria. International Journal of Rock Mechanics and Mining Sciences. 2008;45:1176-86.

[66] Mulders FMM. Modelling of stress development and fault slip in and around a producing gas reservoir [Ph.D. Thesis]. Delft: TU Delft; 2003.

[67] Moeck I, Kwiatek G, Zimmermann G. Slip tendency analysis, fault reactivation potential and induced seismicity in a deep geothermal reservoir. Journal of Structural Geology. 2009;31:1174-82.

[68] van Wees JD, Buijze L, Van Thienen-Visser K, Nepveu M, Wassing B, Orlic B, et al. Geomechanics response and induced seismicity during gas field depletion in the Netherlands. Geothermics. 2014;52:206-19.

[69] Wyss M. Estimating maximum expectable magnitude of earthquakes from fault dimensions. Geology. 1979;7:336-40.

[70] Wells DL, Coppersmith KJ. New empirical relationships among magnitude, rupture length, rupture width, rupture area, and surface displacement. Bulletin of the Seismological Society of America. 1994;84:974-1002.

[71] Leonard M. Earthquake fault scaling: Self-consistent relating of rupture length, width, average displacement, and moment release. Bulletin of the Seismological Society of America. 2010;100:197188.

[72] Douglas J, Jousset P. Modeling the difference in ground-motion magnitude-scaling in small and large earthquakes. Seismological Research Letters. 2011;82:504-8. 
[73] Scholz CH. Earthquakes and friction laws. Nature. 1998;391:37-42.

[74] Dieterich JH. Modeling of rock friction 1. Experimental results and constitutive equations. Journal of Geophysical Research. 1979;84:2161-8.

[75] Ruina A. Slip instability and state variable friction laws. Journal of Geophysical Research. 1983;88:10359-70.

[76] Dieterich J. A constitutive law for rate of earthquake production and its application to earthquake clustering. Journal of Geophysical Research. 1994;99:2601-18.

[77] Zielke O, Arrowsmith JR. Depth variation of coseismic stress drop explains bimodal earthquake magnitude-frequency distribution. Geophysical Research Letters. 2008;35:L24301.

[78] Allmann BP, Shearer PM. Spatial and temporal stress drop variations in small earthquakes near Parkfield, California. Journal of Geophysical Research. 2007;112:B04305.

[79] Jones LE, Helmberger DV. Seismicity and stress-drop in the Eastern Transverse Ranges, southern California. Geophysical Research Letters. 1996;23:233-6.

[80] Goertz-Allmann BP, Goertz A, Wiemer S. Stress drop variations of induced earthquakes at the Basel geothermal site. Geophysical Research Letters. 2011;38.

[81] Abercrombie RE. Earthquake source scaling relationships from -1 to $5 \mathrm{ML}$ using seismograms recorded at 2.5-km depth. Journal of Geophysical Research. 1995;100:24015-36.

[82] Kanamori H, Brodsky EE. The physics of earthquakes. Reports on Progress in Physics. 2004;67:1429-96.

[83] Kwiatek G, Plenkers K, Dresen G, Group JR. Source Parameters of Picoseismicity Recorded at Mponeng Deep Gold Mine, South Africa: Implications for Scaling Relations. Bulletin of the Seismological Society of America. 2011;101:2592-608.

[84] Snow DT. A parallel plate model of fractured permeable media [Ph.D. Thesis]: Berkeley, California; 1965.

[85] Witherspoon PA, Wang JSY, Iwai K, Gale JE. Validity of Cubic Law for fluid flow in a deformable rock fracture. Water Resources Research. 1980;16:1016-24.

[86] Auradou H, Drazer G, Hulin JP, Koplik J. Permeability anisotropy induced by the shear displacement of rough fracture walls. Water Resources Research. 2005;41:W09423.

[87] Bagheri M, Settari A. Modeling of geomechanics in naturally fractured reservoirs. SPE Reservoir Evaluation \& Engineering. 2008;11:108-18.

[88] Jaeger JC, Cook NGW, Zimmermann R. Fundamentals of rock mechanics, 4th edition. Oxford: Blackwell publishing; 2007.

[89] Barton N, Bandis S, Bakhtar K. Strength, Deformation and Conductivity Coupling of Rock Joints. International Journal of Rock Mechanics and Mining Sciences. 1985;22:121-40.

[90] Willis-Richards J, Watanabe K, Takahashi H. Progress toward a stochastic rock mechanics model of engineered geothermal systems. J Geophys Res-Sol Ea. 1996;101:17481-96.

[91] Chen X, Tan CP, Haberfield CM. Numerical evaluation of the deformation behaviour of thickwalled hollow cylinders of shale. International Journal of Rock Mechanics and Mining Sciences. 2000;37:947-61.

[92] Rudnicki JW. Fluid mass sources and point forces in linear elastic diffusive solids. Mechanics of Materials. 1986;5:383-93.

[93] Kohl T, Mégel T. Predictive modeling of reservoir response to hydraulic stimulations at the European EGS site Soultz-sous-Forêts. International Journal of Rock Mechanics and Mining Sciences. 2007;44:1118-31.

[94] Baisch S, Harjes HP. A model for fluid-injection-induced seismicity at the KTB, Germany. Geophysical Journal International. 2003;152:160-70.

[95] Dorbath L, Cuenot N, Genter A, Frogneux M. Seismic response of the fractured and faulted granite of Soultz-sous-Forêts (France) to $5 \mathrm{~km}$ deep massive water injections. Geophysical Journal International. 2009;177:653-75.

[96] Kohl T, Evans KF, Hopkirk RJ, Jung R, Rybach L. Observation and simulation of non-Darcian flow transients in fractured rock. Water Resources Research. 1997;33:407-18.

[97] Shimizu H, Murata S, Ishida T. The distinct element analysis for hydraulic fracturing in hard rock considering fluid viscosity and particle size distribution. International Journal of Rock Mechanics and Mining Sciences. 2011;48:712-27. 
[98] Gens A, Vaunat J, Garitte B, Wileveau Y. In situ behaviour of a stiff layered clay subject to thermal loading: observations and interpretation. Geotechnique. 2007;57:207-28.

[99] Wang HF. Theory of Linear Poroelasticity with Application to Geomechanics and Hydrogeology: Princeton University Press; 2000.

[100] Biot MA. General theory of three dimensionally consolidation. Journal of Applied Physics. 1941;12:155.

[101] Biot MA. Mechanics of Deformation and Acoustic Propagation in Porous Media. Journal of Applied Physics. 1962;33(4):1482-98.

[102] Rice JR, Cleary MP. Some basic stress diffusion solutions for fluid-saturated elastic porous media with compressible constituents. Reviews of Geophysics. 1976;14:227-41.

[103] Norris A. On the correspondence between poroelasticity and thermoelasticity. Journal of Applied Physics. 1992;71:1138-41.

[104] Nowacki W. Thermoelasticity. 2. ed., rev. and enlarged ed. Oxford [u.a.]: Pergamon Pr. [u.a.]; 1986.

[105] Kurashige M. A thermoelastic theory of fluid-filled porous materials. International Journal of Solids and Structures. 1989;25:1039-52.

[106] McTigue DF. Thermoelastic Response of Fluid-Saturated Porous Rock. Journal of Geophysical Research-Solid Earth and Planets. 1986;91:9533-42.

[107] Palciauskas VV, Domenico PA. Characterization of drained and undrained response of thermally loaded repository rocks. Water Resources Research. 1982;18:281-90.

[108] Wang YL, Papamichos E. Conductive Heat-Flow and Thermally-Induced Fluid-Flow around a Well Bore in a Poroelastic Medium. Water Resources Research. 1994;30:3375-84.

[109] Ghassemi A, Tarasovs S, Cheng AHD. A 3-D study of the effects of thermomechanical loads on fracture slip in enhanced geothermal reservoirs. International Journal of Rock Mechanics and Mining Sciences. 2007;44:1132-48.

[110] Koh J, Roshan H, Rahman SS. A numerical study on the long term thermo-poroelastic effects of cold water injection into naturally fractured geothermal reservoirs. Computers and Geotechnics. 2011;38:669-82.

[111] Rutqvist J. Status of the TOUGH-FLAC simulator and recent applications related to coupled fluid flow and crustal deformations. Computers \& Geosciences. 2011;37:739-50.

[112] Tsang C-F. Coupled hydromechanical-thermochemical processes in rock fractures. Reviews of Geophysics. 1991;29:537-51.

[113] Rutqvist J, Stephansson O. The role of hydromechanical coupling in fractured rock engineering. Hydrogeol J. 2003;11:7-40.

[114] Okada Y. Internal deformation due to shear and tensile faults in a half-space. Bulletin of the Seismological Society of America. 1992;82:1018-40.

[115] Wang RJ, Martín FL, Roth F. Computation of deformation induced by earthquakes in a multilayered elastic crust--FORTRAN programs EDGRN/EDCMP. Computers \& Geosciences. 2003;29:195207.

[116] Wang RJ, Lorenzo-Martin F, Roth F. PSGRN/PSCMP - a new code for calculating co- and postseismic deformation, geoid and gravity changes based on the viscoelastic-gravitational dislocation theory. Computers \& Geosciences. 2006;32:527-41.

[117] King GCP, Stein RS, Lin J. Static stress changes and the triggering of earthquakes. Bulletin of the Seismological Society of America. 1994;84:935-53.

[118] Stein RS, Barka AA, Dieterich JH. Progressive failure on the North Anatolian fault since 1939 by earthquake stress triggering. Geophysical Journal International. 1997;128:594-604.

[119] Heidbach O, Ben-Avraham Z. Stress evolution and seismic hazard of the Dead Sea Fault System. Earth and Planetary Science Letters. 2007;257:299-312.

[120] Catalli F, Meier M-A, Wiemer S. The role of Coulomb stress changes for injection-induced seismicity: The Basel enhanced geothermal system. Geophysical Research Letters. 2013;40:72-7.

[121] Yamashita T. Simulation of seismicity due to fluid migration in a fault zone. Geophysical Journal International. 1998;132:674-86. 
[122] McClure M, Horne RN. Discrete Fracture Modeling of Hydraulic Stimulation in Enhanced Geothermal Systems. 35th Workshop on Geothermal Reservoir Engineering. Stanford, California, February 1-3 2010.

[123] Baisch S, Vörös R, Rothert E, Stang H, Jung R, Schellschmidt R. A numerical model for fluid injection induced seismicity at Soultz-sous-Forêts. International Journal of Rock Mechanics and Mining Sciences. 2010;47:405-13.

[124] Scotti O, Cornet FH. In-situ evidence for fluid-induced aseismic slip events along fault zones. International Journal of Rock Mechanics and Mining Sciences. 1995;31:347-58.

[125] Cornet FH, Helm J, H P, Etchecopar A. Seismic and aseismic slips induced by large-scale fluid injections. Pure and Applied Geophysics. 1997;150:563-83.

[126] Bourouis S, Bernard P. Evidence for coupled seismic and aseismic fault slip during water injection in the geothermal site of Soultz (France), and implications for seismogenic transients. Geophysical Journal International. 2007;169:723-32.

[127] Calò M, Dorbath C, Cornet FH, Cuenot N. Large-scale aseismic motion identified through 4-D Pwave tomography. Geophysical Journal International. 2011;186:1295-314.

[128] Schoenball M, Dorbath L, Gaucher E, Wellmann JF, Kohl T. Change of stress regime during geothermal reservoir stimulation. Geophysical Research Letters. 2014;41:1163-70.

[129] McClure MW, Horne RN. Investigation of injection-induced seismicity using a coupled fluid flow and rate/state friction model. Geophysics. 2011;76:WC181-WC98.

[130] Moreno M, Haberland C, Oncken O, Rietbrock A, Angiboust S, Heidbach O. Locking of the Chile subduction zone controlled by fluid pressure before the 2010 earthquake. Nature Geosci. 2014;7:292-6.

[131] Miller SA, Collettini C, Chiaraluce L, Cocco M, Barchi M, Kaus BJP. Aftershocks driven by a highpressure $\mathrm{CO} 2$ source at depth. Nature. 2004;427:724-7.

[132] Bächler D, Kohl T. Coupled thermal-hydraulic-chemical modelling of enhanced geothermal systems. Geophysical Journal International. 2005;161:533-48.

[133] Jing Z, Watanabe K, Willis-Richards J, Hashida T. A 3-D water/rock chemical interaction model for prediction of HDR/HWR geothermal reservoir performance. Geothermics. 2002;31:1-28.

[134] Hayashi K, Willis-Richards J, Hopkirk RJ, Niibori Y. Numerical models of HDR geothermal reservoirs--a review of current thinking and progress. Geothermics. 1999;28:507-18.

[135] McClure MW, Horne RN. The effect of fault zone development on induced seismicity. 37th Workshop on Geothermal Reservoir Engineering. Stanford University, Stanford, California, Jan. 30 Feb. 12012.

[136] Zang A, Yoon JS, Stephansson O, Heidbach O. Fatigue hydraulic fracturing by cyclic reservoir treatment enhances permeability and reduces induced seismicity. Geophysical Journal International. 2013;195:1282-7.

[137] Yoon JS, Zang A, Stephansson O. Numerical investigation on optimized stimulation of intact and naturally fractured deep geothermal reservoirs using hydro-mechanical coupled discrete particles joints model. Geothermics. 2014;52:165-84.

[138] Shapiro SA, Huenges E, Borm G. Estimating the crust permeability from fluid-injection-induced seismic emission at the KTB site. Geophysical Journal International. 1997;131:F15-F8.

[139] Shapiro SA, Audigane P, Royer J-J. Large-scale in situ permeability tensor of rocks from induced microseismicity. Geophysical Journal International. 1999;137:207-13.

[140] Shapiro SA, Rothert E, Rath V, Rindschwentner J. Characterization of fluid transport properties of reservoirs using induced microseismicity. Geophysics. 2002;67:212-20.

[141] Rothert E, Shapiro SA. Microseismic monitoring of borehole fluid injections: Data modeling and inversion for hydraulic properties of rocks. Geophysics. 2003;68:685-9.

[142] Schoenball M, Müller TM, Müller BIR, Heidbach O. Fluid-induced microseismicity in prestressed rock masses. Geophysical Journal International. 2010;180:813-9.

[143] Cornet FH, Yin J. Analysis of Induced Seismicity for Stress Field Determination and Pore Pressure Mapping. Pure and Applied Geophysics. 1995;145:677-700.

[144] Sanjuan B, Pinault J-L, Rose P, Gérard A, Brach M, Braibant G, et al. Tracer testing of the geothermal heat exchanger at Soultz-sous-Forêts (France) between 2000 and 2005. Geothermics. 2006;35:622-53. 
[145] Evans KF, Moriya H, Niitsuma H, Jones RH, Phillips WS, Genter A, et al. Microseismicity and permeability enhancement of hydrogeologic structures during massive fluid injections into granite at $3 \mathrm{~km}$ depth at the Soultz HDR site. Geophysical Journal International. 2005;160:389-412.

[146] Baisch S, Weidler R, Voros R, Wyborn D, de Graaf L. Induced seismicity during the stimulation of a geothermal HFR reservoir in the Cooper Basin, Australia. Bulletin of the Seismological Society of America. 2006;96:2242-56.

[147] Dershowitz WS, Einstein HH. Characterizing rock joint geometry with joint system models. Rock Mechanics and Rock Engineering. 1988;21:21-51.

[148] Bak P, Tang C. Earthquakes as a Self-Organized Critical Phenomenon. Journal of Geophysical Research. 1989;94:15635-7.

[149] Tensi HM. The Kaiser-effect and its scientific background. Journal of Acoustic Emission. 2004;22:S1-S16.

[150] Cundall PA. Fluid-rock interaction program (FRIP): computer model of HDR reservoir. Phase 2 Group IV Part 2 report. CSM Geothermal Energy Project: CSM Geothermal Energy Project Report; 1983.

[151] Pine RJ, Batchelor AS. Downward migration of shearing in jointed rock during hydraulic injections. International Journal of Rock Mechanics and Mining Sciences \&amp; Geomechanics Abstracts. 1984;21:249-63.

[152] Bruel D. Using the migration of induced seismicity as a constraint for fractured Hot Dry Rock reservoir modeling. International Journal of Rock Mechanics and Mining Sciences. 2007;44:1106-17.

[153] Bruel D. Impact of induced thermal stresses during circulation tests in an engineered fractured geothermal reservoir - Example of the Soultz-sous-Forets European Hot Fractured Rock Geothermal Project, Rhine Graben, France. Oil Gas Sci Technol. 2002;57:459-70.

[154] Kayad Moussa A, Bruel D. Role of temperature change in micro seismicity activity during fluid injections in faulted and fractured zones. Part 1: Updating the thermal modelling in a DFN model using a double media approach. 3rd East African Rift Geothermal Conference ARGEO-C3-DJIBUTI. Djibuti, Djibuti 2010.

[155] Jing Z, Willis-Richards J, Watanabe K, Hashida T. A three-dimensional stochastic rock mechanics model of engineered geothermal systems in fractured crystalline rock. Journal of Geophysical Research. 2000;105:23663-79.

[156] Jing L, Stephansson O. Fundamentals of discrete element methods for rock engineering: theory and applications: Elsevier; 2007.

[157] Kohl T, Evans KF, Hopkirk RJ, Rybach L. Coupled hydraulic, thermal and mechanical considerations for the simulation of hot dry rock reservoirs. International Journal of Rock Mechanics and Mining Sciences and Geomechanics Abstracts. 1995;33:130A-A.

[158] McClure M, Horne RN. Numerical and Analytical Modeling of the Mechanisms of Induced Seismicity During Fluid Injection. Geothermal Resources Council Transactions: Geothermal Resources Council; 2010. p. 381-96.

[159] Ghassemi A, Nygren A, Cheng A. Effects of heat extraction on fracture aperture: A porothermoelastic analysis. Geothermics. 2008;37:525-39.

[160] Yoon JS, Zang A, Stephansson O. Simulating fracture and friction of Aue granite under confined asymmetric compressive test using clumped particle model. International Journal of Rock Mechanics and Mining Sciences. 2012;49:68-83.

[161] Itasca. PFC2D, Particle Flow Code in 2 Dimensions. Minneapolis, Minnesota: Itasca Consulting Group; 1999.

[162] Hazzard JF, Young RP. Moment tensors and micromechanical models. Tectonophysics. 2002;356:181-97.

[163] Hazzard JF, Young RP. Dynamic modelling of induced seismicity. International Journal of Rock Mechanics and Mining Sciences. 2004;41:1365-76.

[164] Itasca. FLAC3D, Fast Lagrangian Analysis of Continua in 3 Dimensions, Version 4.0. Minneapolis, Minnesota: Itasca Consulting Group; 2009.

[165] Wassing BBT, van Wees JD, Fokker PA. Coupled continuum modeling of fracture reactivation and induced seismicity during enhanced geothermal operations. Geothermics. 2014;52:153-64. 
[166] Rutqvist J, Oldenburg CM. Analysis of Injection-Induced Micro-Earthquakes in a Geothermal Steam Reservoir, The Geysers Geothermal Field, California. 42th US Rock Mechanics / Geomechanics Symposium. San Franscisco, California, USA, June 29-Jul 2 Americal Rock Mechanics Association ARMA; 2008.

[167] Pruess K, Oldenburg CM, Moridis G. TOUGH2 User's Guide, Version 2.0. Berkeley, California, USA: Lawrence Berkeley National Laboratory; 1999.

[168] Jeanne P, Rutqvist J, Vasco D, Garcia J, Dobson PF, Walters M, et al. A 3D hydrogeological and geomechanical model of an Enhanced Geothermal System at The Geysers, California. Geothermics. 2014;51:240-52.

[169] Angus DA, Kendall JM, Fisher QJ, Segura JM, Skachkov S, Crook AJL, et al. Modelling microseismicity of a producing reservoir from coupled fluid-flow and geomechanical simulation. Geophysical Prospecting. 2010;58:901-14.

[170] Crook AJL, Willson SM, Yu JG, Owen DRJ. Predictive modelling of structure evolution in sandbox experiments. Journal of Structural Geology. 2006;28:729-44.

[171] Silver PG, Jordan TH. Optimal estimation of scalar seismic moment. Geophysical Journal of the Royal Astronomical Society. 1982;70:755-87.

[172] Zoback ML, Zoback M. State of stress in the conterminous United-States. Journal of Geophysical Research. 1980;85:6113-56.

[173] Yoon JS, Zang A, Stephansson O. Simulation of hydraulic stimulation of fractured reservoir and induced seismicity using discrete element-fracture network model. 38th Workshop on Geothermal Reservoir Engineering. Stanford University, Stanford, California, Feb. 11-13 2013.

[174] Hakimhashemi AH, Schoenball M, Heidbach O, Zang A, Grünthal G. Forward modelling of seismicity rate changes in georeservoirs with a hybrid geomechanical-statistical prototype model. Geothermics. 2014;52:185-94.

[175] Shapiro SA, Dinske C, Kummerow J. Probability of a given-magnitude earthquake induced by a fluid injection. Geophysical Research Letters. 2007;34:L22314.

[176] Shapiro SA, Dinske C. Scaling of seismicity induced by nonlinear fluid-rock interaction. Journal of Geophysical Research. 2009;114:B09307.

[177] Rothert E, Shapiro SA. Statistics of fracture strength and fluid-induced microseismicity. Journal of Geophysical Research. 2007;112:B04309.

[178] Dinske C, Shapiro S. Seismotectonic state of reservoirs inferred from magnitude distributions of fluid-induced seismicity. Journal of Seismology. 2013;17:13-25.

[179] Barth A, Wenzel F, Langenbruch C. Probability of earthquake occurrence and magnitude estimation in the post shut-in phase of geothermal projects. Journal of Seismology. 2013;17:5-11.

[180] Goertz-Allmann B, Wiemer S. Geomechanical modeling of induced seismicity source parameters and implications for seismic hazard assessment. Geophysics. 2013;78:KS25-KS39.

[181] Cuenot N, Frogneux M, Dorbath C, Calò M. Induced microseismic activity during recent circulation tests at the EGS site of Soultz-sous-Forêts (France). 36th Workshop on Geothermal Reservoir Engineering. Stanford University, Stanford, California, Jan. 31 - Feb. 22011.

[182] Megies T, Wassermann J. Microseismicity observed at a non-pressure-stimulated geothermal power plant. Geothermics. 2014;52:36-49.

[183] Schorlemmer D, Wiemer S, Wyss M. Earthquake statistics at Parkfield: 1 . Stationarity of b values. Journal of Geophysical Research. 2004;109:B12307.

[184] Schorlemmer D, Wiemer S. Earth science: Microseismicity data forecast rupture area. Nature. 2005;434:1086-.

[185] Marone C. Laboratory-derived friction laws and their application to seismic faulting. Annual Review of Earth and Planetary Sciences. 1998;26:643-96.

[186] Wellmann JF, Regenauer-Lieb K. Uncertainties have a meaning: Information entropy as a quality measure for 3-D geological models. Tectonophysics. 2012;526-529:207-16.

[187] Hampel A, Günther RM, Salzer K, Minkley W, Pudewills A, Leuger B, et al. Benchmarking of geomechanical constitutive models for rock salt. 2010.

[188] Buiter SJH, Babeyko AY, Ellis S, Gerya TV, Kaus BJP, Kellner A, et al. The numerical sandbox: comparison of model results for a shortening and an extension experiment. Geological Society, London, Special Publications. 2006;253:29-64. 
[189] Kohl T, Hopkirk RJ. "FRACTure" - A simulation code for forced fluid flow and transport in fractured, porous rock. Geothermics. 1995;24:333-43.

[190] Rabemanana V, Durst P, Bächler D, Vuataz F-D, Kohl T. Geochemical modelling of the Soultzsous-Forêts Hot Fractured Rock system: comparison of two reservoirs at 3.8 and $5 \mathrm{~km}$ depth. Geothermics. 2003;32:645-53.

[191] Hazzard JF, Young RP, Oates SJ. Numerical modelling of seismicity induced by fracture injections in a fractured reservoir. Proceedings of the 5th North American Rock Mechanics Symposium. Toronto, Canada University of Toronto Press; 2002. p. 1023-30.

[192] Rutqvist J, Oldenburg CM, Dobson PF, Garcia J, Walters M. Predicting the Spatial Extent of Injection-Induced Zones of Enhanced Permeability At the Northwest Geysers EGS Demonstration Project. In: Association ARM, editor. 44th US Rock Mechanics Symposium and 5th US-Canada Rock Mechanics Symposium. Salt Lake City, Utah, June 27-30 2010.

[193] Itasca. 3DEC, 3 Dimensional Distinct Element Code, Version 4.0, User's Manual. Minneapolis, Minnesota: Itasca Consulting Group; 2008.

[194] Rachez X, Gentier S. 3D-Hydromechanical behavior of a stimulated fractured rock mass. World Geothermal Congress. Bali, Indonesia 2010. 
Figure 1: Forecasting approaches of induced seismicity in geothermal fields.

Figure 2: Overview of the processes, properties, field values, and parameters involved in the elaboration of geothermal-induced seismicity forecasting. The workflows of the cataloguebased, physics-based, or hybrid approaches are also shown through the coloured arrows. All forecasting approaches deliver a synthetic catalogue of forecasted induced seismicity. THM(C) stands for thermo-hydro-mechanical(-chemical); (X) or (t) highlight parameters, which are space- or time-dependent, respectively.

Figure 3: Excerpt from Figure 6 of Bachmann et al. [35]. Seismicity rates within the next six hours as a function of time for three models (E2, E4, and E5) based on ETAS approach with flow rate. The observed rate is indicated by a bold black line and circles. The time of the shut-in and the two largest events that led to actions within the traffic-light system are indicated.

Figure 4: According to Figure 8 of Bachmann et al. [35]. Probabilities within the next 6 hours for events of magnitudes greater than 2,3 , and 4 as a function of time, based on model E5. Observed events above magnitude 2 are indicated in the lower panel.

Figure 5: Contributions to the stress field. The contributions can be divided into three main parts that act on different temporal and spatial scales.

Figure 6: Mohr-Coulomb failure criterion. The perimeters of the Mohr circles denote the boundaries of the effective shear stress $(\tau)$ and the normal stress $\left(\sigma_{n}\right)$ as a function of the orientation of fault planes. The normal stresses are limited by the lower and larger effective normal stresses $\left(\sigma_{3}\right.$ and $\left.\sigma_{1}\right)$. An increase of pore pressure by $\Delta p$ would decrease the effective stress and can lead to failure of an existing fault. A fault is critically stressed when the ratio of shear stress and normal stress is close to the coefficient of friction $(\mu)$, corresponding to the slope of the failure envelope. For a given effective normal stress, failure on an existing fault usually happens for smaller shear stresses (orange line) than failure of the intact rock (red line) which in addition have cohesion (c).

Figure 7: Schematic representation of the coupled thermo-hydro-mechanical-chemical processes relevant to induced seismicity in geothermal applications.

Figure 8: Typical pore fluid pressure evolution, over time and space, according to a Darcynian diffusive flow (grey curves), after Rudnicki's model [92], and according to a fracture-dominated flow (black curves), after Kohl and Mégel's model [93]. A two-step flow rate is applied (grey area). Pressure profiles offset from the injection well are shown: well $(r=0), r=10 \mathrm{~m}$ and $r=100 \mathrm{~m}$ for the diffusive flow, and well $(r=0), r=500 \mathrm{~m}$ for the fracture-dominated flow. Note the linear increase of the pressure with the flow rate and the very fast decline of the pressure with distance from the well for a diffusive model (grey curves). In a fracture mechanics model (black curves), the pressure increase is highly non-linear and high pressures can still be observed even at large distances.

Figure 9: Distribution of the pore pressure due to water injection in a fault which is not critically stressed (left) and which is more critically stressed (right), as modelled by Wassing et al. [165]. 

Table 1: Numerical simulators of stress change and induced seismicity relevant to geothermal fields. The models are sorted according to their appearing order in the text (see section 4.4). "FE" stands for finite element, "FD" for finite-differences, "DEM" for distinct element method, "BEM" for boundary element method, "HM" for hydro-mechanical process, "THM" for thermohydro-mechanical process, "THMC" for thermo-hydro-mechanical and chemical process. 


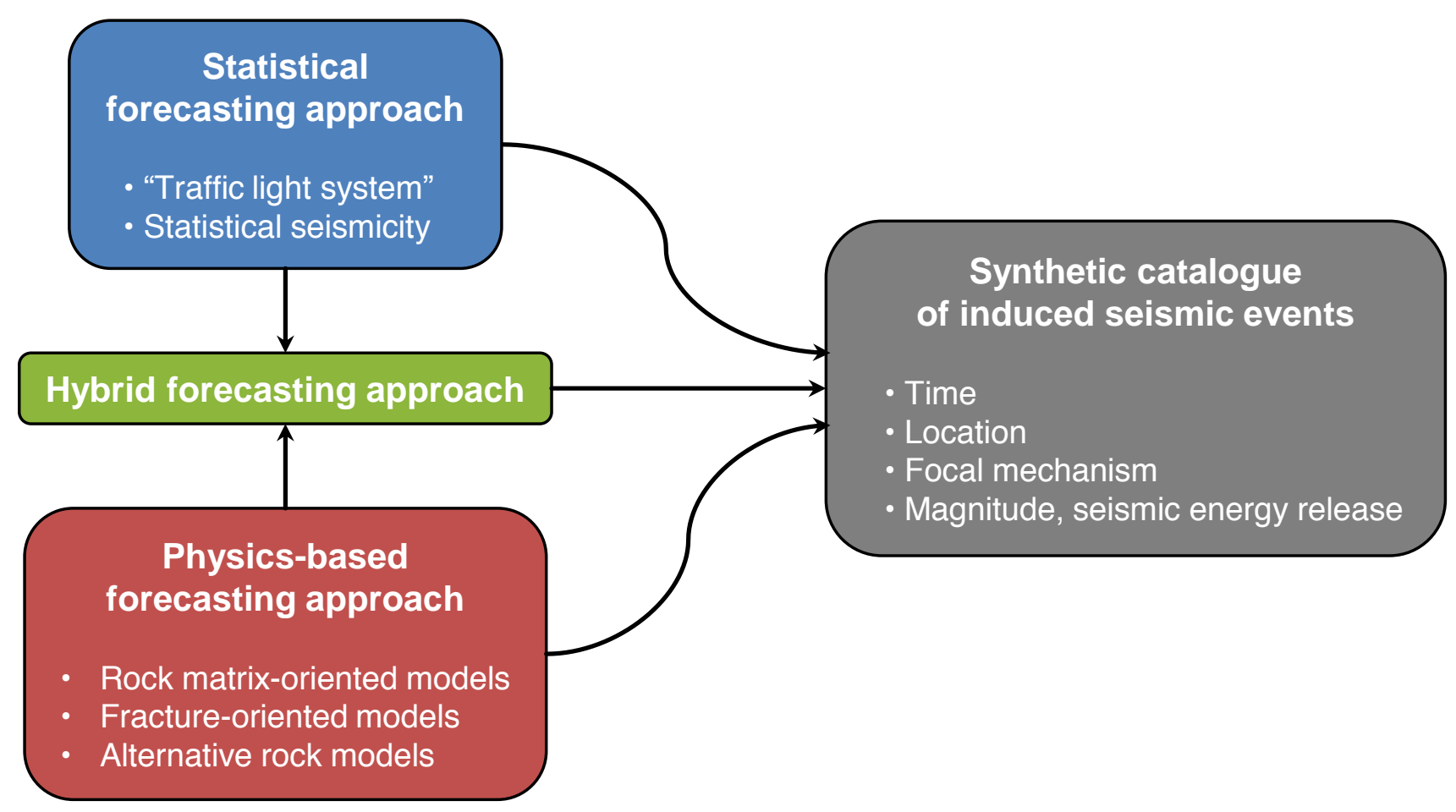


Figufe2

$\because$ Statistical

Physics-based

Hybrid
Static

Unperturbed state

\section{Dynamic}

Perturbed state

Geothermal operation

- Stimulation

- Injection

- Production

- Circulation

\section{Reservoir} Structure and Properties

Geometrical features

- Deterministic major faults

- Stochastic fractures (DFN)

- Wells

\section{Properties}

- Density

- Porosity

- Permeability

- Thermal expansion coef.

- Thermal conductivity

- Elastic moduli

Initial conditions $\mathrm{T}, \mathrm{p}, \sigma$

\section{Observations} Geology, Geodesy, Geophysics, Geomechanics

\section{THM(C) process modelling}

THM(C) dynamic characteristics Stress field perturbation

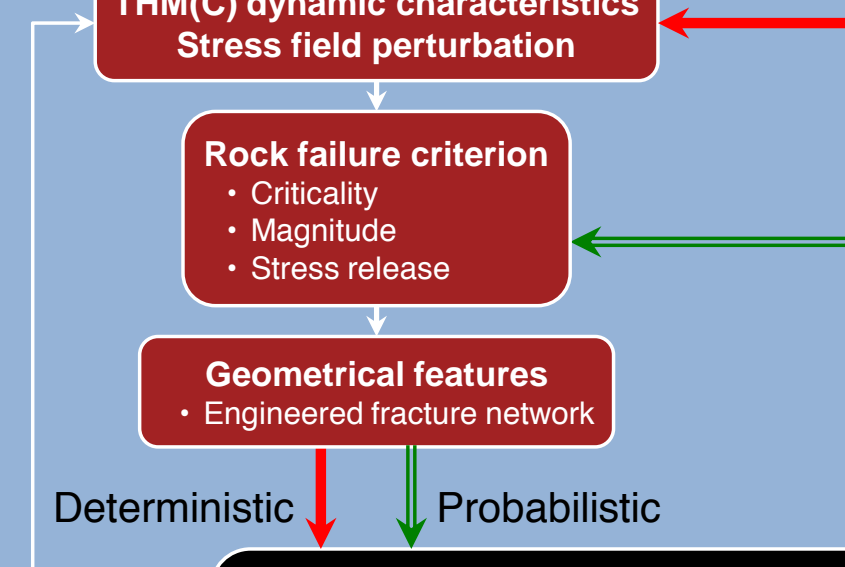

Synthetic catalogue of induced seismic events - Time

- Location

- Focal mechanism

- Magnitude, seismic energy release

THM(C) observations

- $T(X), Q(X), P(X)$

- Fluid(X)

- Logging $(X)$

- Imaging $(X)$

- Tectonic loading rates

- $S_{H \max }$ orientation

- $S_{\text {hmin }}$ magnitudes

- Stress regime

- $\mathrm{V}_{\mathrm{p}}, \mathrm{V}_{\mathrm{s}}$ velocities

Background seismicity

Frequency magnitude distribution $\mathrm{M}_{\max }$

- Focal mechanisms

- Seismic energy release

\section{THM(C) observations}

- $\quad \mathrm{T}(\mathrm{t}, \mathrm{X}), \mathrm{Q}(\mathrm{t}, \mathrm{X}), \mathrm{P}(\mathrm{t}, \mathrm{X})$

Fluid(t,X)

- Strain rates

- Stress changes

Induced seismicity

Frequency magnitude distribution $(\mathrm{t})$

Location(t)

Focal mechanisms

Seismic energy release

Probabilistic

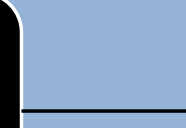

round motion

prediction equations

$\downarrow$

Probabilistic seismic

hazard assessment
Exposure $\downarrow$

Seismic risk 


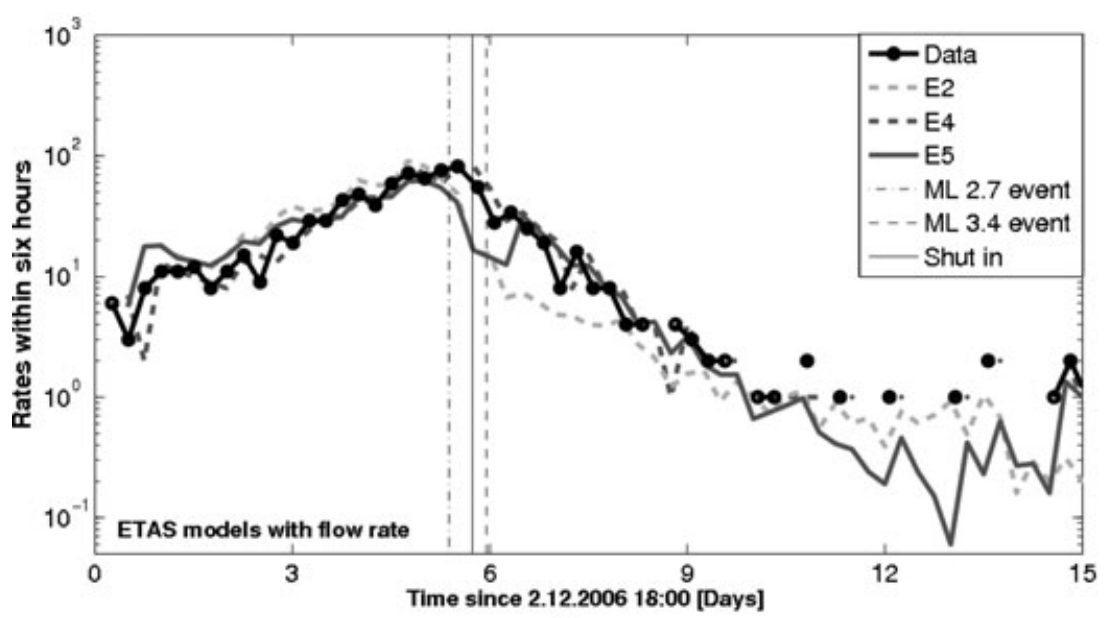




\section{Probability of events within six hours, based on E5}

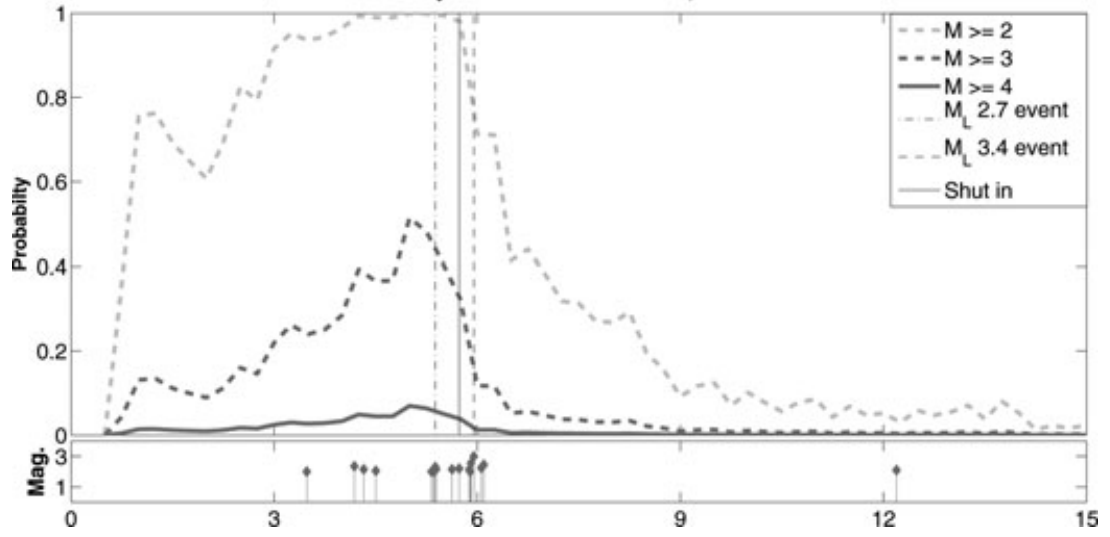




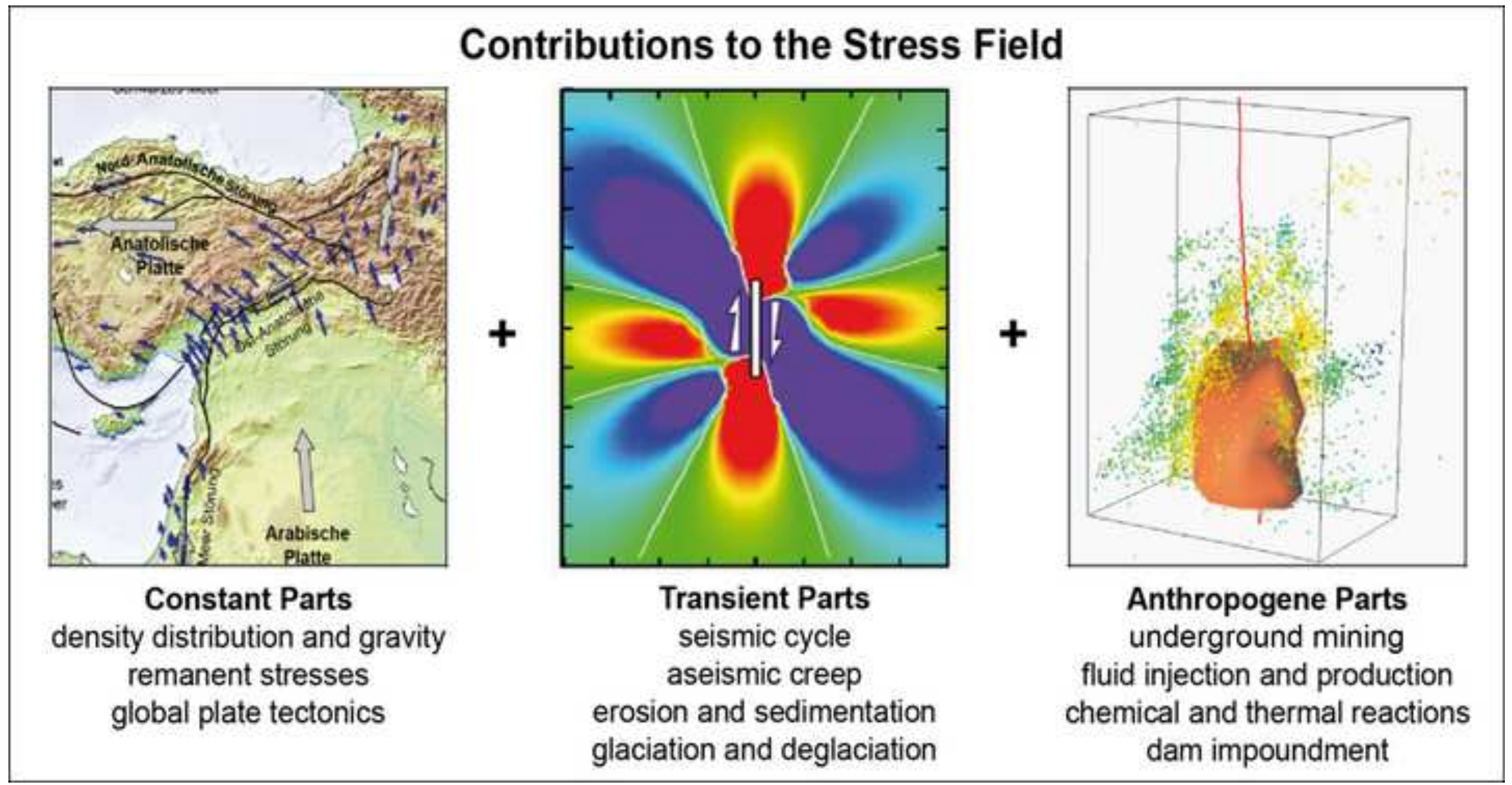




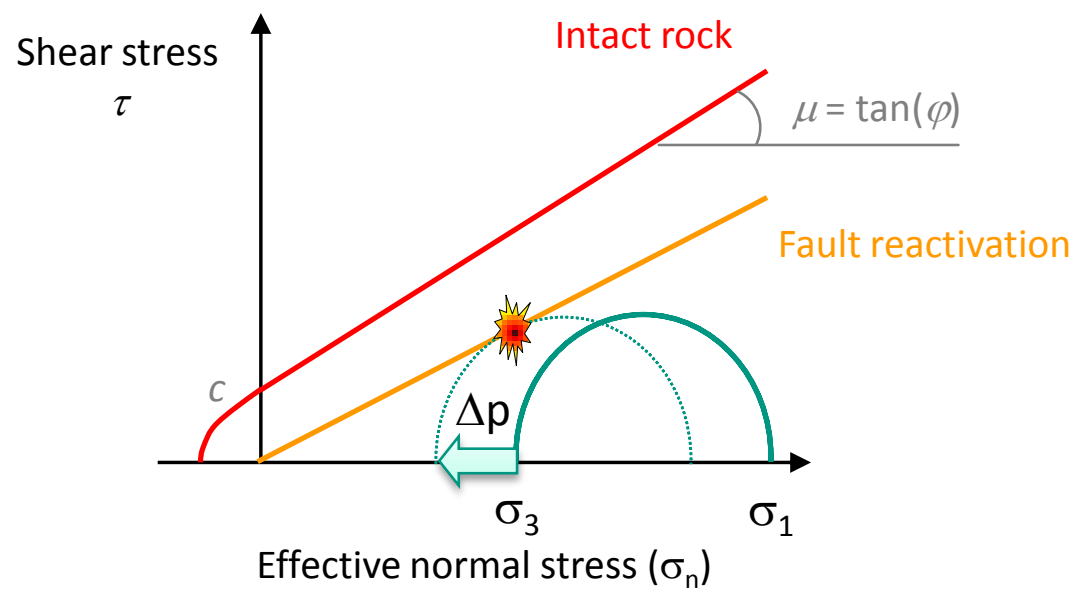




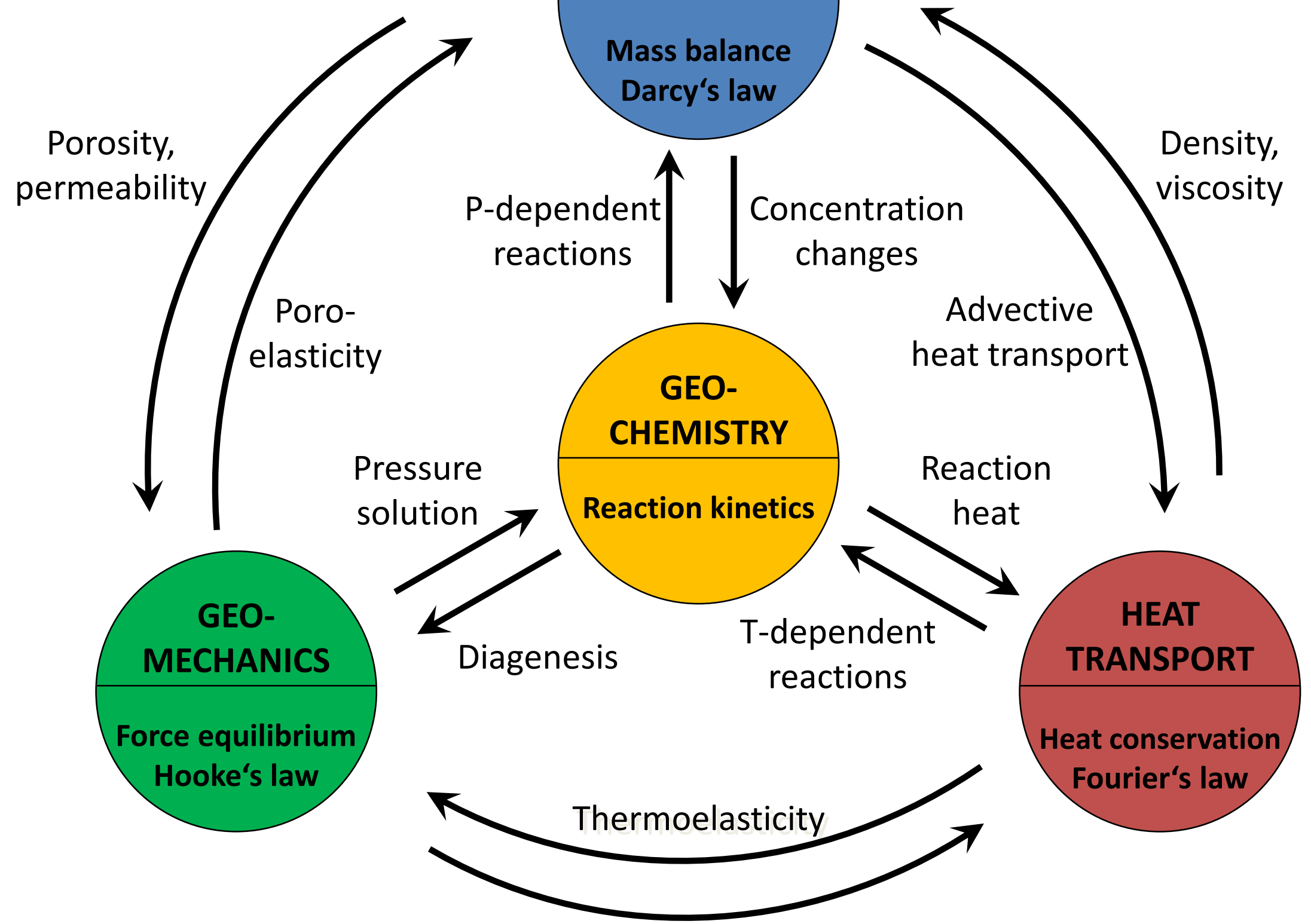

Frictional heating 
Figure9

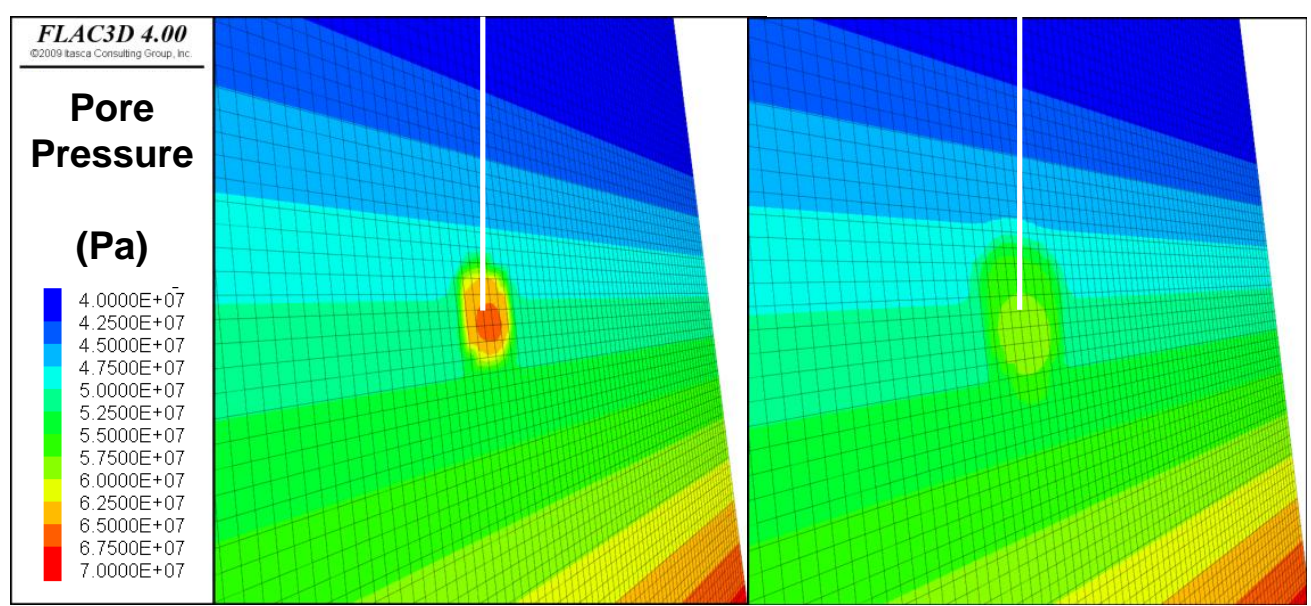


Table 1: Numerical simulators of stress change and induced seismicity relevant to geothermal fields. The models are sorted according to their appearing order in the text (see section Error! Reference source not found.). "FE" stands for finite element, "FD" for finite-differences, "DEM" for distinct element method, "BEM" for boundary element method, "HM" for hydro-mechanical process, "THM" for thermo-hydro-mechanical process, "THMC" for thermohydro-mechanical and chemical process.

\begin{tabular}{|c|c|c|c|c|c|c|c|}
\hline Model & Coupled processes & $\begin{array}{l}\text { Numerical } \\
\text { method }\end{array}$ & Fracture network & Fluid flow & Permeability creation & Slipping surface & Rupture propagation \\
\hline $\begin{array}{l}\text { Rothert and Shapiro } \\
\text { [142] }\end{array}$ & $\begin{array}{l}\text { Pore pressure } \\
\text { diffusion }\end{array}$ & $\begin{array}{l}2 \mathrm{D} F \mathrm{E} \text {, effective } \\
\text { medium }\end{array}$ & None & Diffusive in matrix & None & $\begin{array}{l}\text { None, evaluation of } \\
\text { Coulomb criterion } \\
\text { on regular grid }\end{array}$ & None \\
\hline Schoenball et al. [143] & $\begin{array}{l}\text { Fully coupled } \\
\text { poroelasticity }\end{array}$ & $\begin{array}{l}\text { 2D FE, effective } \\
\text { medium }\end{array}$ & None & Diffusive in matrix & None & $\begin{array}{l}\text { None, evaluation of } \\
\text { Coulomb criterion } \\
\text { on regular grid }\end{array}$ & Over time steps \\
\hline Baisch et al. [125] & $\begin{array}{l}\text { Pore pressure } \\
\text { diffusion } \\
\text { HM }\end{array}$ & & Single fault in $2 \mathrm{D}$ & $\begin{array}{l}\text { Diffusive along } \\
\text { fracture }\end{array}$ & Opening + Shearing & $\begin{array}{l}\text { Slip patches }(20 \times 20 \\
\mathrm{m})\end{array}$ & $\begin{array}{l}\text { Redistribution of stresses in } \\
\text { block-spring-model }\end{array}$ \\
\hline Yamashita [123] & Poroelasticity & 2D-FD & Single fault in $2 \mathrm{D}$ & $\begin{array}{l}\text { Diffusive along } \\
\text { fracture }\end{array}$ & $\begin{array}{l}\text { Varying thickness of } \\
\text { fluid conduit (?) }\end{array}$ & $\begin{array}{l}\text { Fault segments, } 500 \\
\mathrm{~m}\end{array}$ & $\begin{array}{l}\text { Static stress change from slip } \\
\text { on segment }\end{array}$ \\
\hline $\begin{array}{l}\text { FRIP } \\
\text { Pine and Batchelor [151] }\end{array}$ & THM & 2D-FD & Rectangular grid & ?? & Opening + Shearing & Block elements & Over time steps \\
\hline $\begin{array}{l}\text { FRACAS } \\
\text { Bruel [152] }\end{array}$ & $\begin{array}{l}\text { THM } \\
\text { Fracture mechanics }\end{array}$ & $\begin{array}{l}\text { 3D Boundary } \\
\text { Integral Equation } \\
\text { Method }\end{array}$ & Stochastic fractures & $\begin{array}{l}\text { Cubic law } \\
\text { 3D pipe network }\end{array}$ & Opening + Shearing & Slip patches & Over time steps \\
\hline $\begin{array}{l}\text { FRACSIM-3D } \\
\text { Jing et al. }[135,155] \\
\text { Willis-Richards et al [92] }\end{array}$ & $\begin{array}{l}\text { THMC } \\
\text { (not fully coupled) }\end{array}$ & $3 D-F D$ & Stochastic fractures & Cubic law & Opening + Shearing & Stochastic fractures & Over time steps \\
\hline
\end{tabular}




\begin{tabular}{|c|c|c|c|c|c|c|c|}
\hline $\begin{array}{l}\text { FRACTure } \\
\text { Kohl and Hopkirk [188] } \\
\text { Rabemanana et al. [189] }\end{array}$ & THMC & $\begin{array}{l}\text { 3D-FE, Effective } \\
\text { medium }\end{array}$ & $\begin{array}{l}\text { Discretized } \\
\text { Fractures as } 2 D \text { and } \\
1 D \text { elements in } 3 D \\
\text { matrix }\end{array}$ & $\begin{array}{l}\text { Diffusive in 1D, 2D } \\
\text { and 3D elements } \\
\text { Turbulence in } \\
\text { fractures }\end{array}$ & Normal opening & None & None \\
\hline $\begin{array}{l}\text { HEX-S } \\
\text { Kohl and Mégel [95] }\end{array}$ & $\begin{array}{l}\text { Hydro- and Fracture } \\
\text { mechanics }\end{array}$ & $\begin{array}{l}\text { 3D FE } \\
\text { Effective media } \\
\text { mapping } \\
\text { fractures }\end{array}$ & $\begin{array}{l}\text { Discrete Fracture } \\
\text { Network in 3D with } \\
\text { deterministic } \\
\text { stochastic fractures }\end{array}$ & $\begin{array}{l}\text { Cubic law mapped } \\
\text { on matrix }\end{array}$ & $\begin{array}{l}\text { Opening + Shearing } \\
{[92]}\end{array}$ & Slip patches $(40 \mathrm{~m})$ & Over time steps \\
\hline $\begin{array}{l}\text { McClure and Horne [137, } \\
\text { 158] }\end{array}$ & $\begin{array}{l}\text { Thermohydraulics } \\
\text { Fracture mechanics }\end{array}$ & $\begin{array}{l}\text { Boundary } \\
\text { Element and } \\
\text { Finite Volume } \\
\text { Methods }\end{array}$ & $\begin{array}{l}\text { 2D Stochastic } \\
\text { fracture network }\end{array}$ & Cubic law & Opening + Shearing & Slip patches & $\begin{array}{l}\text { Rate-and-state friction } \\
\text { Static stress change }\end{array}$ \\
\hline Koh et al. [112] & $\begin{array}{l}\text { Fully coupled } \\
\text { thermo- } \\
\text { poroelasticity } \\
\text { Fracture mechanics }\end{array}$ & $\begin{array}{l}\text { 2D FE } \\
\text { Effective media } \\
\text { mapping } \\
\text { fractures }\end{array}$ & $\begin{array}{l}\text { Stochastic fracture } \\
\text { network }\end{array}$ & $\begin{array}{l}\text { Cubic law mapped } \\
\text { on matrix }\end{array}$ & Opening + Shearing & $\begin{array}{l}\text { Discretized fracture } \\
\text { segments }\end{array}$ & Over time steps \\
\hline Ghassemi et al. [111] & THM & 3D-BEM, FD & $\begin{array}{l}\text { Single fault in } 3 D \\
\text { medium }\end{array}$ & Cubic law (?) & Opening + Shearing & $\begin{array}{l}\text { Fracture mesh } \\
\text { elements }\end{array}$ & Over time steps \\
\hline Hazzard et al. [190] & Full HM & 2D-DEM & $\begin{array}{l}\text { Along particle } \\
\text { contacts, } \\
\text { continuous }\end{array}$ & Cubic law & Breaking of bonds & $\begin{array}{l}\text { Particle contacts, c. } \\
20 \mathrm{~m}\end{array}$ & $\begin{array}{l}\text { Stress transfer through } \\
\text { particle flow }\end{array}$ \\
\hline Wassing et al [164] & $\begin{array}{l}\text { Hydro- and fracture } \\
\text { mechanics }\end{array}$ & $3 D-F D$ & $\begin{array}{ll}\text { Single fault with } \\
\text { ubiquitous } \\
\text { model }\end{array}$ & $\begin{array}{l}\text { Diffusive along } \\
\text { fracture }\end{array}$ & $\begin{array}{l}\text { Opening and closing } \\
\text { fractures, tensile and } \\
\text { shear }\end{array}$ & $\begin{array}{l}\text { Fault segments, } 50 \\
\mathrm{~m}\end{array}$ & Slip weakening \\
\hline $\begin{array}{l}\text { TOUGH-FLAC } \\
\text { Rutqvist [113] } \\
\text { Rutqvist et al. [191] }\end{array}$ & $\begin{array}{l}\text { Fully coupled } \\
\text { thermo- } \\
\text { poroelasticity }\end{array}$ & $3 D-F D$ & $\begin{array}{l}\text { Discretized } \\
\text { fractures }\end{array}$ & $\begin{array}{l}\text { Diffusive in matrix } \\
\text { and fault elements } \\
\text { (?) }\end{array}$ & $\begin{array}{l}\text { Function of porosity } \\
\text { Special hydraulic } \\
\text { elements }\end{array}$ & Interface elements & Over time steps \\
\hline
\end{tabular}




\begin{tabular}{|c|c|c|c|c|c|c|c|}
\hline $\begin{array}{l}\text { 3DEC [192] } \\
\text { Rachez and Gentier [193] }\end{array}$ & $\begin{array}{l}\text { Hydro- and Fracture } \\
\text { mechanics }\end{array}$ & 3D-DEM & $\begin{array}{l}\text { Discretized } \\
\text { fractures }\end{array}$ & Cubic law & Opening + Shearing & $\begin{array}{l}\text { Discretized fracture } \\
\text { segments }\end{array}$ & Over time steps \\
\hline Angus et al. [168] & $\begin{array}{l}\text { Constitutive rock } \\
\text { model }\end{array}$ & 3D-FE/DEM & Discretized faults & $\begin{array}{l}\text { Diffusive in matrix } \\
\text { and fault elements } \\
\text { (?) }\end{array}$ & Compaction coupling & $\begin{array}{l}\text { None, evaluation of } \\
\text { Coulomb criterion } \\
\text { on regular grid }\end{array}$ & Over time steps \\
\hline Yoon et al. [44] & Fracture mechanics & 3D-DEM & $\begin{array}{l}\text { Bonded particles } \\
\text { break in tension and } \\
\text { shear }\end{array}$ & $\begin{array}{l}\text { Dry, hydro- } \\
\text { mechanically } \\
\text { coupled fracturing } \\
\text { optional }\end{array}$ & $\begin{array}{l}\text { Tensile and shear } \\
\text { cracks }\end{array}$ & $\begin{array}{l}\text { Pre-existing cracks } \\
\text { are simulated by } \\
\text { unbounded contacts }\end{array}$ & $\begin{array}{l}\text { Is simulated by process zone } \\
\text { cracks forming the shear } \\
\text { failure path }\end{array}$ \\
\hline
\end{tabular}

